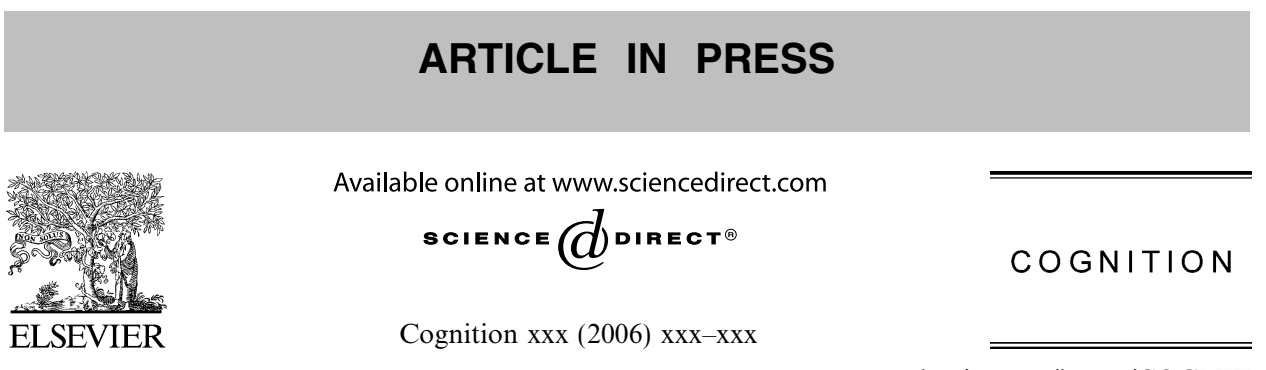

www.elsevier.com/locate/COGNIT

\title{
The biology and evolution of music: A comparative perspective
}

\author{
W. Tecumseh Fitch * \\ School of Psychology, University of St. Andrews, St. Andrews, Fife, KY16 9JP, UK
}

\begin{abstract}
Studies of the biology of music (as of language) are highly interdisciplinary and demand the integration of diverse strands of evidence. In this paper, I present a comparative perspective on the biology and evolution of music, stressing the value of comparisons both with human language, and with those animal communication systems traditionally termed "song". A comparison of the "design features" of music with those of language reveals substantial overlap, along with some important differences. Most of these differences appear to stem from semantic, rather than structural, factors, suggesting a shared formal core of music and language. I next review various animal communication systems that appear related to human music, either by analogy (bird and whale "song") or potential homology (great ape bimanual drumming). A crucial comparative distinction is between learned, complex signals (like language, music and birdsong) and unlearned signals (like laughter, ape calls, or bird calls). While human vocalizations clearly build upon an acoustic and emotional foundation shared with other primates and mammals, vocal learning has evolved independently in our species since our divergence with chimpanzees. The convergent evolution of vocal learning in other species offers a powerful window into psychological and neural constraints influencing the evolution of complex signaling systems (including both song and speech), while ape drumming presents a fascinating potential homology with human instrumental music. I next discuss the archeological data relevant to music evolution, concluding on the basis of prehistoric bone flutes that instrumental music is at least 40,000 years old, and perhaps much older. I end with a brief review of adaptive functions proposed for music, concluding that no one selective force (e.g., sexual selection) is adequate to explaining all aspects of human music. I suggest that questions about
\end{abstract}

\footnotetext{
* Fax: +441334463042.

E-mail address: wtsf@st-andrews.ac.uk.
} 


\section{ARTICLE IN PRESS}

the past function of music are unlikely to be answered definitively and are thus a poor choice as a research focus for biomusicology. In contrast, a comparative approach to music promises rich dividends for our future understanding of the biology and evolution of music.

(c) 2005 Elsevier B.V. All rights reserved.

\section{Introduction}

There has recently been a surge of interest in the biology and evolution of music or "biomusicology" (Avanzini, Faienza, Minciacchi, Lopez, \& Majno, 2003; Peretz \& Zatorre, 2003; Wallin, Merker, \& Brown, 2000; Zatorre \& Peretz, 2001). Human music is based upon a diverse set of perceptual mechanisms, some shared with most other vertebrates, and therefore with a very long evolutionary history, and some potentially unique to our species. For example, goldfish can learn to distinguish baroque music from blues (Chase, 2001), suggesting that some mechanisms involved in music perception date back to the earliest jawed vertebrates (some 500 million years ago). In contrast, even nonhuman primates seem unable to recognize melodies as purely relational structures, as does a newborn child, suggesting that this aspect of music perception evolved in the last few million years (D'Amato, 1988; Hauser \& McDermott, 2003). Although all of the mechanisms involved in music perception and production may be grouped together, for convenience, as "the music faculty" or "the capacity for music", it is important to remember that different components of this capacity may have different evolutionary histories. Thus, discussing "Music" as an undifferentiated whole, or as a unitary cognitive "module", risks overlooking the fact that music integrates a wide variety of domains (cognitive, emotional, perceptual, motor,...), may serve a variety of functions (mother-infant bonding, mate choice, group cohesion...) and may share key components with other systems like language or speech. Thus, questions like "When did music evolve?" or "What is music for?" seem unlikely to have simple unitary answers.

In this paper, I will discuss the biology and evolution of music from an explicitly multicomponent perspective, distinguishing particularly between vocal song and instrumental music. I offer some ways of defining these components, and review the comparative literature for evidence as to when, how and why, some of them evolved. I will argue that the comparative database, while still far from complete, is sufficiently rich today to lead to some interesting conclusions and further hypotheses about human music. I will stress the importance of the pluralistic approach to biological questions urged by Tinbergen (Tinbergen, 1963), who distinguished four categories of answers: mechanistic, developmental, phylogenetic and functional. Thus, the simple question "Why do birds sing?" has many correct answers, all of which are important for a complete understanding of birdsong. At a mechanistic level, birds sing because they have a complex vocal organ and neural song circuits that are activated when hormone levels are high. Other mechanistic possibilities (e.g., the bird sings because singing feels good, or to enjoy the song's beauty), although harder to address experimentally, may also be valid. Developmentally, the bird sings because it was raised in an environment full of conspecific songs, which 


\section{ARTICLE IN PRESS}

it learned (many birds will not sing properly otherwise). Phylogenetically, all birds share a syrinx, indicating that this unique vocal organ evolved near the beginning of bird evolution. Finally, functionally (adaptively), birds sing because their ancestors who sang out-reproduced those that did not. This may have been because they attracted more or better mates, defended better territories, or both.

Crucially, Tinbergen stressed that all four types of question are equally valid and interesting. The four domains are essentially orthogonal, and their answers independent. Although adaptive questions in the last category are fascinating, they are typically the hardest of Tinbergen's four categories to address. One reason for this is the lability of function: the evolutionary function(s) of a particular trait often change substantially over time (cf. Reeve \& Sherman, 1993) a phenomenon termed "exaptation" (Gould, 1991; Gould \& Vrba, 1982). Three examples directly relevant to music include the mammalian middle ear bones, which started as jaw supports but now function in audition, the vertebrate laryngeal cartilages, which began as gill supports but now function in sound production, and the lungs, which are homologous to the swim bladder in fish, a floatation control system, but are used in breathing and vocalization in tetrapods. Such lability has led some theorists to advocate a notion of "adaptation" which ignores past function (Reeve \& Sherman, 1993), but while the difficulty of extrapolating from current to past function is widely acknowledged, most conceptions of adaptation still involve historical function in some way (WestEberhard, 1992). Thus, although experiments addressing current utility can be performed (e.g., for birdsong, see below), these do not necessarily demonstrate ancestral function. Even for birdsong, which has been intensively studied, the outcomes are often ambiguous (Kroodsma \& Byers, 1991). For human music, an activity whose current utility is quite obscure, adaptive questions appear even more challenging. However, it is important to realize that functional questions concerning adaptation (particularly past or "original" function) do not need to be answered for productive research to proceed on mechanistic, developmental and phylogenetic questions. Thus, although I will briefly review adaptive hypotheses of music in this paper, I will stress their tentative nature, the lack of convincing evidence concerning any of them, and the independence of progress in biomusicology from their answers.

Another theme of this paper will be the value of comparisons between music and language to a richer biological understanding of both. For example, vocal learning is a prerequisite of both song and speech, and the study of vocal learning in animals thus may shed light on both of these distinctive human behaviours. There are both deep similarities and quite obvious differences between music and language, both of which are uniquely human considered in toto, but each of which involves ancient mechanisms shared with other animals. Recent trends in biolinguistic research offer some valuable lessons for the newer field of biomusicology, and suggest that the similarities and differences between music and language could profitably be more intensively exploited, both theoretically and experimentally. Ultimately, we might expect more rapid progress in understanding the biology of music, because music has better analogs in the natural world (e.g., bird or whale "song", convergently evolved) and because several human musical abilities have plausible homologous precursors in our primate relatives. But at present, discussions of the biology and evolution of lan- 


\section{ARTICLE IN PRESS}

W.T. Fitch / Cognition $x x x$ (2006) $x x x-x x x$

guage have progressed further, and thus biolingustics provides a context and framework for my discussion here (Fitch, 2005; Hauser, Chomsky, \& Fitch, 2002).

\section{Comparative approaches to music}

A comparative approach to music has at least three sides. The first and oldest type of comparison is inter-cultural, among human musics: the topic of a vast literature in comparative musicology and ethnomusicology. Cross-cultural data are clearly an important prerequisite to the search for musical universals, one arm of a biological approach to characterizing the capacity for music. However, as many book-length reviews of this field are already available I will not attempt to review this large topic here, but will simply make use of its results (see Blacking, 1976; Kunst, 1974; Merriam, 1964; Nettl, 1983; Sachs, 1940; Titon, Koetting, McAllester, Reck, \& Slobin, 1984). The second comparison, also within our own species, is that between music and language (and other allied systems like dance and poetry). I will discuss this intraspecific comparison between cognitive domains in some detail in the next section. Finally, the comparisons between human music, both vocal and instrumental, and "musical" behaviours of various sorts among animals will be the second and main focus of my review here (which will focus on vertebrates). I will argue that, when properly delimited, animal signaling systems provide a rich source of insights into the biology of human music, with both homologous systems (e.g., bimanual drumming in great apes) and analogous systems (e.g., birdsong) available for further detailed study.

\subsection{Linguistic comparisons: Design features of human music}

In a classic paper, (Hockett, 1960) outlined a number of characteristics of language which he called "design features". These are listed in Table 1. By singling out particular aspects of language as points of comparison with animal communication systems, Hockett's paper provided a spur to further research in animal communication, with the outcome that several features he believed to be unique to human language were subsequently documented in animals. Hockett also discussed instrumental music in his paper but excluded vocal music (without explanation), and his discussion thus forms a reasonable starting place for a dissection of music into sub-components. For this comparison, I must obviously exclude lyrical music, which because it incorporates language thus automatically inherits any linguistic design features. Thus, in this context, I mean by "vocal music" all music generated by the vocal tract but lacking distinct words (e.g., humming, jazz "scat" singing, Central Asian formant singing, etc.).

As is clear in Table 1, most of Hockett's design features of language are shared by music (interchangeability is an interesting exception). Furthermore, most of the nonshared features appear to derive from one core difference between music and language: referentiality or "semanticity". Language can be used to convey an unlimited set of discrete, propositional meanings, and music cannot. While music is typically 


\section{ARTICLE IN PRESS}

W.T. Fitch / Cognition $x x x$ (2006) $x x x-x x x$

Table 1

Hockett's (1960) design features of language

\begin{tabular}{llll}
\hline Language & Music & & Innate human calls \\
\cline { 2 - 3 } Design feature & Instrumental & Vocal & \\
\hline 1. Vocal auditory channel & No & Yes & Yes \\
2. Broadcast transmission & Yes & Yes & Yes \\
3. Rapid fading & Yes & Yes & Yes \\
4. Interchangeability & No & Yes? & Yes \\
5. Total feedback & Yes & Yes & Yes \\
6. Specialization & Yes & Yes & Yes \\
7. Semanticity & No & No & No? \\
8. Arbitrariness & No & No & No? \\
9. Displacement & No & No & No \\
10. Duality of patterning & No & No & No \\
11. Productivity & Yes & Yes & No \\
12. Discreteness & Yes & Yes & No \\
13. Cultural transmission & Yes & Yes & No \\
\hline
\end{tabular}

Design features of language Hockett (1960). Thirteen features all argued by Hockett to be present in spoken language, as compared with instrumental and vocal music, and innate human calls (e.g., laughter, crying, screaming, moaning...).

Brief explanations of non-obvious terms (see Hockett (1960) for detailed description and discussion): 4 , interchangeability (one can say anything one can understand vs. not all saxophone listeners can play the instrument); 5 , total feedback (you hear what you're saying or playing); 6 , specialization (signal "triggers" desired results with negligible direct energy expenditure; unlike forcing someone manually); 7 , semanticity (words associated with things); 9, discreteness (digital vs. analog); 10, displacement (a capacity to refer to non-present objects or events); 11, productivity (novelty, also tied to counterfactuality); 12, duality of patterning (meaningless elements combine to produce a large number of meaningful elements).

composed of a discrete set of fundamental units (notes and beats), these do not map onto equally discrete meanings semantically. The lack of this form of meaning in music directly leads to the absence of arbitrariness, displacement and duality of patterning (combination of meaningless elements into meaningful words, and thence to sentences). Thus, for example, music lacks duality of patterning by definition, because neither "A\#" nor a sequence of notes "means anything" in the same way that "dog" does. Although certain types of music may blur this distinction (e.g., the use of motives to signify a character or season in Western music, or the use of drummed patterns or whistled speech to imitate language) these seem both clearly marginal to human music in general, and plausibly "parasitic" on language in the same way as is lyrical music. Thus as a first approximation, Hockett's framework would characterize vocal music as "speech minus meaning". This difference in referentiality between music and language does not imply that music has no meaning, of course, but simply that the mapping between signal and interpretation is quite different in music and language. Indeed, it seems likely that the affective and aesthetic power of music derives from these differences. Music, rather than being semantically deficient relative to language, encourages a complementary mode of interpretation that is a major source of its appeal (Cross, 2003). Thus, it is more accurate to characterize music as being like language without propositional, combinatorial meaning. 


\section{ARTICLE IN PRESS}

Of course, from a musicological point of view, characterizing music by what it lacks relative to language seems limited, if not derogatory. Music has its own unique features as well, elements that language lacks. As a first step in the direction of characterizing human music in its own terms, I will now propose some design features of music, based on results from ethnomusicology (e.g., Arom, 2000; Nettl, 2000). Unfortunately, ethnomusicologists have traditionally been wary or even hostile to the search for musical universals for largely historical and sociological reasons (Nettl, 1983, 2000), in rather sharp contrast to linguistics where the search for universals is considered productive and respectable. Thus, this list of "design features of music" is intended to provide a concrete basis for the comparative discussion below, and for future discussions, but is not intended to be definitive or exhaustive. In Table 2 I present a list of some suggested basic "design features" of music. The first three features are shared with language. By complexity I mean that musical signals (like linguistic signals) are more complex than the various innate vocalization available in our species (groans, sobs, laughter and shouts). Although complexity can be measured and quantified in various ways (see, e.g., Homer \& Selman, 2001; Shmulevich \& Povel, 2000; Simon, 1972; Weng, Bhalla, \& Iyengar, 1999), there is no single widely used metric applicable to all musics (Pressing, 1998), so it would be premature to specify any absolute threshold for "complexity" at present. Oddly, Hockett did not include complexity on his list of design features, although its necessity for language is implicit in his discussion. A signal at a certain level of complexity is clearly a prerequisite for conveying an unlimited number of complex meanings, and therefore a pre-requisite for human language. Second, music, like language, is generative: it uses rule-governed combinations and permutations of a limited number of "notes" or "syllables" to generate an unlimited number of hierarchically structured signals (Merker, 2002). Note that a second component of linguistic "generativity" (in the technical sense), a symmetry between listener and speaker that Hockett termed "interchangeability", is not typically present in instrumental music. One can understand and appreciate a viola or an oboe performance despite being unable to play either instrument. In contrast, any human has a basic capacity to sing, and an ability to reproduce basic melodies vocally, if not beautifully, appears to be an

Table 2

Design features of music

\begin{tabular}{lll}
\hline Design feature & Language? & Innate calls? \\
\hline 1. Complexity & Yes & No \\
2. Generativity & Yes & No \\
3. Culturally transmitted & Yes & No \\
4. Discrete Pitches & No & No \\
5. Isochronic & No & No \\
6. Transposability & Yes & $?$ \\
7. Performative context & No & No \\
8. Repeatable (repertoire) & No & No \\
9. A-referentially expressive & No & Yes \\
\hline
\end{tabular}

Proposed design features of human music (see text Section 2.1 for explanation and discussion). 


\section{ARTICLE IN PRESS}

early developing human universal. Finally, musical styles, like individual languages, are learned by experience and thus culturally transmitted.

Music also differs from language (and innate calls) in several important ways (cf. Merker, 2002). The most obvious is that most of the world's musics rely on a discrete set of pitches - a scale - from which notes are chosen to build melodies (Nettl, 2000). Although there are exceptions (e.g., some singing styles, or in some rhythmic African music where defined pitch is absent), this is a key feature differentiating song (with discrete pitch) from speech (with continuously variable pitch). Second, in the temporal domain, music tends to be isochronic, meaning that there is a regular periodic pulse (also termed the beat, or tactus) which provides a reference framework for other temporal features of the music (Arom, 2000; Merker, 2002). Note that isochronicity is a relative feature: virtually no music is perfectly isochronous, and some musical styles rather freely vary the underlying pulse. Although there are some styles of speech which use an isochronic framework (e.g., ritualistic speech or poetry), and certain non-isochronic musical genres (e.g., sung lament), isochronicity is a core feature of most of the world's musics. Thus, the clearest differences between music and language are that music relies on a discretization of both pitch and time, while in language production both are free to vary continuously. Discrete time and pitch make music more acoustically predictable than language, and thus enhance acoustic integration between multiple individuals in an ensemble, or between notes in harmonic music.

A feature of musical melody that is shared with language is that musical pitch structures are transposable: a melody is considered "the same" when it is performed or sung on a higher starting note. This is because, in human music, a melody is defined by the relationships between notes, not just the absolute frequencies of the individual notes. Thus, two singers with very different pitch ranges (e.g., a man and a woman) can still sing the "same" melody, despite using a different set of pitches to do so. The same is true of speech (although pitches are not discrete in speech): a sentence spoken by a woman is "the same" as one spoken by a man an octave lower. This free transposability may represent a key difference between human and animal melody perception (D'Amato, 1988; Hauser \& McDermott, 2003) (but see Wright, Rivera, Hulse, Shyan, \& Neiworth, 2000). It is less clear that innate calls possess transposability: is high-pitched tittering laughter the same as a similar signal at a lower pitch? I have left this undecided in Table 2.

Three further proposed design features of music differentiate music from language less clearly. First, human music typically occurs in specific performative contexts: particular songs or styles recur in specific social contexts, especially ritualistic contexts stressing supernatural or mystical themes (Arom, 2000; Cross, 2003; Nettl, 2000). These contexts vary considerably from culture to culture: Western classical music may have very specific contexts (e.g., the opera house) compared to folk musics (Nettl, 1995), but all cultures seem to differentiate celebratory music from dirges or laments, men's music from women's music, lullabies from work songs, or draw some similar distinctions. This leads to a second unusual feature of music: that songs or performances are typically repeated (often with great frequency) in the 


\section{ARTICLE IN PRESS}

appropriate context: a musical system contains a repertoire of different, identifiable pieces (Nettl, 1983). Unlike spoken utterances, musical performances are typically repeatable, without any obvious decrement (and sometimes an increment) in enjoyment. One might listen to the Beatles "Let it Be" or Beethoven's "Moonlight Sonata" scores of times, and keep coming back for more. Language is different. One may enjoy seeing the same play or movie several times, and children sometimes seem to have an endless appetite for repeated stories, but the vast majority of linguistic utterances are uttered once and never repeated. There is an interesting area of overlap between these two features of music and language however, in ritual language such as prayers, blessings, invocations, etc., or in theatrical performances and traditional storytelling. Finally, so called "phatic" communication such as greetings or farewells, are highly repeatable. However, such formulaic utterances have often been singled out by linguists as peculiar (Wray, 2002), and their very similarity to music seems to differentiate them from ordinary language.

The final proposed design feature is easily the most difficult to pinpoint, and the topic of a vast, ancient and controversial literature: the question of meaning in music (see also Jackendoff \& Lerdahl, in press). On the one hand, as discussed above, music is clearly not meaningful in the way language is (able to convey an unlimited number of propositional thoughts or "meanings" with arbitrary specificity). On the other hand, music is not meaningless: music is expressive in some different, hard-to-define sense. It is often said that music "expresses the emotions". It is clear both intuitively, and from an increasing body of experimental work, that music can have profound effects on arousal and mood (e.g., Blood \& Zatorre, 2001; Thompson, Schellenberg, \& Husain, 2001), and this is clearly an important component of the "meaning" of music. However, limiting musical meaning to emotion seems insufficiently general, if not procrustean, since music can also be abstracted away from emotion, and the complex cognitive processing involved in music perception is, in an important sense, prior to any experienced emotion (cf. Sloboda, 1985). Furthermore, there is commonly a mapping between music's acoustic form and movement, especially dance (another human universal, (Nettl, 1983)), and this music $\leftrightarrow$ dance mapping is not easily subsumed by the term "emotion" (Cross, 2003). Movement provides objectively measurable ways of examining the expressive nature of music. We can easily match the tempo and "gestural form" (Bierwisch, 1979) of a piece of music to an appropriate sequence of movements in dance, or reject inappropriate mappings, and this demonstrates that some kind of non-arbitrary mappings between the sonic domain of music and various other domains exists (see also Clynes, 1977, 1995; Juslin \& Sloboda, 2001; Trainor \& Schmidt, 2003). Ian Cross has suggested that the difficulty in pinning down the nature of this mapping actually reflects a crucial aspect of musical meaning (Cross, 2003), which is the capacity of music to imbue any situation with meaningfulness, which is nonetheless potentially quite different for different participants; Cross has dubbed this "floating intentionality". Without entering into further discussion I will cautiously denote this final design feature of music, a "gestural form" which includes flexible mappings to both mood and movement, as its capacity to be a-referentially expressive. It is worth noting that, although the primary expressive mode of language is referential and propositional, speech can also express emo- 


\section{ARTICLE IN PRESS}

tionality through paralinguistic aspects of prosody (often appropriately termed "musical" aspects of speech), and there are profound similarities between speech and music in this respect (reviewed in Juslin \& Laukka, 2003).

\subsection{Biological comparisons: Defining animal "song" and "instrumental music"}

As both Darwin and Tinbergen stressed, a crucial component of research on phylogeny and function is the comparative method: the use of data from living species to draw inferences about extinct ancestors and adaptive function. Because the songbird syrinx does not fossilize, the comparative method provides the only evidence about the structure and function of the ancestral syrinx, and much the same can be said of the human larynx. Two types of similarities must be distinguished, homology and analogy, because they support different types of inferences. Homologous traits are present in two or more species by virtue of common descent: they are inherited from a common ancestor (although perhaps in changed form). Homologous characters are critical for deducing phylogeny (systematic relationships among species) and thus are a traditional focus of taxonomic research. For example, we share a large number of homologous characters with our nearest relatives, the chimpanzees, including a propensity to use simple tools. We can thus conclude that our last common ancestor with chimpanzees (the LCA), who lived in Africa some 5-7 million years ago, had a propensity to use tools. The second class of trait is equally important, though typically less well-studied: Analogous traits. These are similar traits that were not present in a common ancestor, but have evolved independently in two lineages. Flight in bats and birds is a good example: the common ancestor of bats and birds was an early terrestrial reptile that could not fly. The many similarities between bats and birds (wings, light weight, high metabolism, etc.) result from parallel selection pressures to excel in the aerial niche, and are the clearest evidence of adaptation to this niche. An important example of an analogous trait is vocal learning in humans and birds, which has evolved separately in multiple lineages (see below). In general, analogous traits provide evidence regarding adaptation while homologous traits reflect ancestry, and both types play important roles in the comparative method.

In the next section, I will offer a more detailed review of some complex animal behaviors that are often considered "musical" or termed "song". But before doing so I will offer some provisional definitions to justify what I do not review. I will not attempt to define human music, considered as a monolithic whole. Despite a long history of attempts no uncontroversial definition is currently accepted, and in any case "music" as a term is both a new one in English, and not shared in various other languages, which may lump "music" with "dance" or "celebration" as a single term (cf. Merker, 2000, 2002; Nettl, 2000). Nonetheless, music in most cultures is easily and unambiguously singled out (from both language, and other vocalizations and activities) by members of that culture (Nettl, 2000). Hence defining human music seems both difficult and unnecessary: we should focus rather on the subcomponents of the music faculty. Here, I will single out two subcomponents of animal musical behaviour that can be readily defined: song and instrumental music (particularly percussion). 


\section{ARTICLE IN PRESS}

\subsubsection{Vocal music or "song"}

The term "music" has traditionally been freely applied to birdsong. Aristotle observed that bird song was learned (Aristotle, 350 BC), and by Darwin's time, the similarities between human and bird "music" were well-enough understood for him to suggest that they are evolutionary analogs (Darwin, 1871). The term "bird song" is used not only by biologists but also musicologists, and this tradition is old (e.g., "bird music" in Scholes, 1938) and continues unbroken until the present day ("animal music", Marler, 2000; Marler \& Slabbekoorn, 2004; Slater, 2001). It was once thought that birdsong is the only form of animal music: "But for humans, birds are perhaps Nature's only musicians", (Scholes, 1938, p. 107), but the recent discovery of complex, learned vocalizations in marine mammals invalidated this belief (Payne \& McVay, 1971). The justification for traditionally singling out birdsong from other animal vocalization (such as frog or cricket calls) has varied. However, two continuous threads can be discerned: birdsong is complex, and it is learned. Various other issues, including tonality, diatonicity or accompaniment by "dance" are often brought up as incidental or aesthetic criteria, but not as definitive of song. Following in this tradition, animal "song" can be defined simply as complex, learned vocalization. Almost coincidentally, this definition of "song" (based on findings in ethology) also applies to humans, with one caveat - that music lacks composite, propositional meaning - necessary only to distinguish it from spoken language.

Some objective definition of this sort is required for productive discussion and further analysis of animal "song". Any definition linking music specifically to humans would be useless in this context, defining away "animal song" by fiat, and requiring us to coin some new term for bird or whale vocalizations. In the same way that defining "flight" independently of phylogeny allows the exploration of convergent adaptation in birds and bats, an objective definition of "song" is a first step towards rigorous comparative analysis. The definition above is simple, including almost all the phenomena traditionally called song (in humans, birds and more recently whales) and excluding most of the inappropriate contenders (e.g., frog or cricket "song", neither of which are learned). Learning can obviously be verified experimentally (e.g., Marler, 1970b; Owren, Dieter, Seyfarth, \& Cheney, 1993). The term "complexity" may seem slippery, but other reasonable possibilities (e.g., "generativity", Marler, 2000) are quite difficult to measure objectively, while complexity can be quantified by various metrics (minimum description length is particularly attractive, e.g. Pressing, 1998; Rissanen, 1997; Weng et al., 1999). Thus, no aesthetic criteria or matters of taste need enter into this definition, and it rejects nothing by fiat: if the complex 36-syllable vocalizations of the Madagascan frog Boophis (Narins, Lewis, \& McClelland, 2000) were shown to be learned, this would constitute "frog song". For the remainder of this article I will drop the quotes and use "animal song" to denote complex, learned vocalizations.

By this definition, song has evolved repeatedly in vertebrates. The classic example, birdsong, is based on an ability to learn vocalizations that has evolved at least three times in birds (songbirds, parrots and hummingbirds (Doupe \& Kuhl, 1999)). I will focus here on songbirds, which are by far the best-understood of these groups. Songbirds (technically termed oscine passerines) represent the most speciose suborder 


\section{ARTICLE IN PRESS}

(oscine) of the largest order of birds (Passeriformes); there are about 4000 songbird species (of about 9000 bird species total). The sister clade of songbirds is the suboscine group, which in general do not learn their display vocalizations (which are nonetheless often called "songs" because of their similar function in mate attraction and territorial defense). It was clear to Darwin, and has remained unargued ever since, that bird song is analogous, not homologous, to human song (our common ancestor, a Paleozoic reptile, did not sing), and the same can be said for whale and seal song. By the definition above, there are no singing primates except humans: although certain primate calls are traditionally termed song (e.g., the complex vocalizations of gibbons (Geissmann, 2000), or the simple but beautiful and haunting call of the indri, a Madagascan prosimian) there is no evidence of vocal learning of complex vocalizations in any nonhuman primate (Janik \& Slater, 1997).

\subsubsection{Instrumental music or "drumming"}

In addition to song, the use of "sound tools" to create music is nearly universal among human cultures (Nettl, 1983). I will define instrumental music as the use of the limbs or other body parts to produce structured, communicative sound, possibly using additional objects. In general in the wild, such behaviours are non-tonal and percussive, and we can freely substitute the term "drumming" (e.g., "ape drumming", or "woodpecker drumming"). In sharp contrast to song, which has evolved repeatedly, instrumental music is quite rare among vertebrates. Intriguingly, however, the best examples are found in our nearest relatives, the African great apes, specifically in chimpanzees (who drum on tree buttresses or other resonant structures as a component of their complex dominance displays (Arcadi, Robert, \& Mugurusi, 2004; Arcadi, Robert, \& Boesch, 1998; Goodall, 1986)) and gorillas (who drum on their bodies, and sometime objects, during aggressive displays and play (Schaller, 1963)). Enculturated bonobos also have considerable instrumental capacities, including both spontaneous rhythmic drumming on objects and playing musical keyboards (Savage-Rumbaugh, pers. comm.). I know of no reports of drumming behaviour in orangutans. Thus, bimanual drumming in African great apes provides an intriguing possibility of a homologue of human instrumental music in our nearest cousins, which evolved after our split from orangutans and gibbons. Further parallels to drumming are quite rare in vertebrates, the most prominent examples being woodpeckers (Dodenhoff, Stark, \& Johnson, 2001; Stark, Dodenhoff, \& Johnson, 1998), or various desert rodent species (e.g., Randall, 1997). The only attested form of instrumental music involving more than one object is by palm cockatoos, who drum against hollow trees with sticks (Wood, 1984, 1988). Because this topic is both poorly studied and rarely mentioned in discussions of the biology of music I will review it in detail in Section 3.4.

\subsubsection{Are human and animal song analogous?}

Despite this long history of considering bird song as an analog to human music, some recent treatments have questioned this (for discussion see Slater, 2001). In particular, a recent paper by Hauser and McDermott rejects the analogy between bird or whale song and human song as of little use, relative to the laboratory studies of 


\section{ARTICLE IN PRESS}

animal music perception they stress (Hauser \& McDermott, 2003, p. 667). These authors give three reasons for this rejection. First, they state that the behavioural context of animal song is "extremely limited" relative to human song, and "defined by its role in the adaptive context of territory defense and mate attraction". But animal song does occur outside of these contexts (e.g., subsong and whisper song, see below) and human music is similarly limited in many cultures (e.g., songs or even whole styles that are only appropriate in church, or at weddings, funerals or birthday parties, or people who sing exclusively in the shower). Such limitations certainly do not disqualify these performances from being "music". More importantly, I see no reason that shared adaptive context should be a pre-requisite of biological analogy: the fact that flight is used in some species to capture prey and in others to escape predation or pursue mates does not make it less analogous. Analogy is a property of mechanisms, and should be based on objective, formal criteria subject to empirical test, not by inferred adaptive function.

Hauser and McDermott's second argument for disqualifying animal song as analogous to human song is that animal song functions solely in communication "with no evidence of solo performances, practice or productions for entertainment", while human singing is "characteristically produced for pure enjoyment". This statement is misleading, because young male songbirds do sing alone, seemingly "practicing" for later adult performances (a behaviour termed "subsong"), and even adult songbirds sometimes sing quietly and alone (termed "whisper song"). Again, it is unclear why adaptive functional considerations should exclude analogy. In any case, to contrast "pure enjoyment" (a proximate causal explanation) with "communicative function" (an ultimate adaptive explanation) is to conflate two separate levels of biological explanation (Tinbergen, 1963).

Finally, Hauser and McDermott reject the analogy between animal and human song because "in most non-human singing species, singing is predominantly a male behaviour, which is not true for humans". But there are many bird species in which females sing as much as males (Langmore, 1998; Riebel, 2003) and some human cultures in which conspicuous musical performances are limited mainly to males (Titon et al., 1984). Although it does appear to be the case that only male whales sing (Croll et al., 2002; Payne \& Payne, 1985), and it is clear that most of the birdsong in temperate regions is performed by males, female song and duetting is much more common in poorly studied tropical species. Since most birds species live in the tropics, our perception of the frequency of female song in birds may be somewhat skewed for accidental historical reasons (Langmore, 1998). But even to the extent that the generalization concerning male song is true, it is unclear why this should disqualify male-specific song from analogy with human song. In many insect species, only males have wings, but this fact provides no grounds for rejecting the analogy between male winged flight with that of other species.

I conclude that none of these arguments provide compelling grounds for rejecting the traditional analogy between human and animal song, dating back to Aristotle and championed by Darwin, Marler and many others. Field or laboratory studies of animal music-making provide a complement to laboratory work on perception, not an alternative. In the next section, I will give an overview of the comparative 


\section{ARTICLE IN PRESS}

data on animal song. Given the objective definition of song I propose, and a circumscribed subset of animal vocalizations to be isolated, it will be seen that the analogy is quite rich. Indeed, I will argue, a careful consideration of animal song provides an empirical basis for hypotheses about both some general constraints on the evolution of complex signaling systems, and specific aspects of musical form that may result from constraints imposed by the vertebrate nervous system by producing and processing such complex signals (e.g., hierarchicality, see Section 3.2).

\section{Literature review: The comparative biology of music}

In this section, I will briefly review comparative data concerning animal musicmaking, in particular "song" and "instrumental music", using the definitions above as my guide. Another source of useful and important data on animal musical abilities comes from laboratory studies examining animals' perception of human music, e.g., the finding that goldfish and pigeons can distinguish between and generalize about musical styles (Chase, 2001; Porter \& Neuringer, 1984), or the difficulties monkeys have in generalizing about melody transpositions other than the octave (D'Amato, 1988; Wright et al., 2000). However, there are several comprehensive reviews of this topic already in the literature (Carterette \& Kendall, 1999; McDermott \& Hauser, 2005), so I will focus here on studies of animal's spontaneous production of "song" or drumming. Because such behaviour can be observed and recorded, the ethological literature on this topic is a rich source of insights into the biology of music.

\subsection{Bird song}

The most obvious analog of human song in the animal world is birdsong. Bird "song" has traditionally been differentiated from other avian vocalizations ("calls") by its complexity and, in songbirds, by the fact that it is learned (Catchpole \& Slater, 1995; Langmore, 1998; Riebel, 2003). Other factors such as seasonality (e.g., singing in the spring), function (e.g., defending a territory) or sex differences (singing mostly by males) are also associated with, but not diagnostic of, song. The existence of song learning was already noted by Aristotle (Aristotle, $350 \mathrm{BC}$ ), and vocal learning provided an important basis for Darwin's suggestion that human and bird "music" are evolutionary analogs (Darwin, 1871). Since that time it has become clear that vocal learning is a key factor, in most bird species, distinguishing song from calls (which are typically innate), and furthermore that vocal learning is a quite rare ability among mammals (Janik \& Slater, 1997). Nonetheless, there are a few types of birds which are said to "sing" on functional grounds (because the vocalization functions in territoriality or courtship) but whose vocalizations are not complex (e.g., doves) or are not learned (some suboscines). I will explicitly exclude such species here. The ability to vocally learn, and the resulting possibility for cultural transmission, dialect formation and the like, is a critical consideration when discussing the analogy with human music (or language). Thus (following my definition of animal song) this discussion is focused only on learned song. 


\section{ARTICLE IN PRESS}

Birds are one of the four classes of terrestrial vertebrates (Class Aves) and they are perhaps the most highly vocal (the other contenders are frogs and toads, Class Amphibia, and some mammals, Class Mammalia). One of the key features differentiating birds from other vertebrates is their vocal organ, called the syrinx, which is possessed by all birds (in at least some form), and only in birds. The syrinx is a complex structure which lies in the chest, at the base of the trachea, between the lungs (for an overview of birdsong production see Suthers, 1999). The syrinx is devoted entirely to sound making, and is highly diverse among different orders of birds (and, often, diagnostically similar within an order King, 1989). The existence of two independent sound sources within the oscine larynx (Greenewalt, 1968; Suthers, 1990) allows these birds to create two completely independent pitches (e.g., to theoretically sing both parts of a Bach two-part invention simultaneously), making the oscine syrinx arguably the most sophisticated vocal instrument known. Although birds have a larynx (which is the sound-producing organ in most vertebrates, including humans), no bird is known to use the larynx to make sounds. Although there is a rough correlation between the complexity of this vocal organ and song complexity (passerine birds have the most complex songs and the most complex syrinx), the relationship is imperfect in that many species with a complex syrinx sing relatively simple songs. However, complexity can vary considerably within closely related clades with identical syringeal anatomy. Thus, neural factors must play a key role in controlling song complexity, with the most important factor being a capacity for vocal learning.

Vocal learning has evolved convergently at least thrice in birds, in songbirds, parrots and hummingbirds (Catchpole \& Slater, 1995). "True" songbirds (oscine passerines) form one large division of passerine birds. The other passerines are called suboscines and generally are not vocal learners. However, there is now evidence of vocal learning in the suboscine bellbirds (Kroodsma, pers. comm.), which would make a fourth group. Thus, song is learned in only three of 23 orders of birds (Passeriformes, Psittaciformes and Trochiliformes). However, these three orders are among the most speciose and account for more than half of the world's bird species. Thus, it is safe to say that birds make up the vast majority of animal species with a capacity for vocal learning. Ethologists have studied birdsong intensively over the last 50 years, and a huge amount is known about the mechanisms, function and ontogeny of birdsong. This makes birdsong a very rich source of comparative data relevant to the biology and evolution of music.

Despite the clear fact that singing is done mainly by males in many species, there is a growing realization of the importance of female singing (Langmore, 1998) and of female perceptual learning (e.g., to differentiate among singing males (Riebel, 2003)). It appears that the traditional assumption that only males sing results partly from historical accident: in temperate regions, male singing is the norm, but in tropical species, both duetting and solo female song increasingly appear to be common or even typical (Morton, 1996). Another intriguing fact is that females of some species that do not normally sing can be induced to sing via male hormone treatment. Thus, the neural mechanisms for song are in place in females (perhaps as part of their song evaluation system), even though not normally expressed. Female song was long overlooked in many temperate species, and female song was often treated as an aberrant, 


\section{ARTICLE IN PRESS}

non-adaptive trait (e.g., Darwin, 1871). If females and males look identical, it was often assumed that a singing individual must be a male. But with laparoscopic sexing and tagging it has become increasingly clear that even in Europe or North America female song is surprisingly common, and a normal feature of the social system in numerous birds. For instance European robin Erithacus rubecula females sing during the autumn to defend winter territories (Kriner \& Schwabl, 1991), and female song typifies the common N. American cardinal Cardinalis cardinalis (Ritchison, 1986). Careful experimentation has revealed both mate attraction and territorial functions for female song in different species (Langmore, 2000), though territoriality appears to predominate (Farabaugh, 1982). Still, true sex role reversal (females displaying and males choosing) is rare, and male song remains in most species with female song. Thus, although few doubt the overarching historical role of sexual selection in the evolution of birdsong, the traditional assumption that birdsong is always a sexually selected trait, dating back to Darwin (Darwin, 1871), may need to be reevaluated in such cases. Because song in humans is sexually egalitarian, with both women and men having the potential to be excellent singers, female bird song is quite relevant to the evolution of song in our own species.

\subsubsection{The adaptive functions of birdsong}

Since Darwin (1871), many authors have based hypotheses about the evolution of human music based on the adaptive functions of birdsong, so it is worth considering this topic in some detail. We know more about the function of birdsong than about any other complex acoustic communication system, and the possibility of doing experiments to test functional hypotheses means that ethologists have gone beyond correlations to make experimental tests of causality (Kroodsma \& Byers, 1991; Searcy \& Yasukawa, 1996). The ability to use hormone treatments, remove males from their territories or mute them, raise birds in isolation or with artificial "tutors", etc., allows some empirically grounded statements about the current utility of birdsong (in sharp contrast to, for example, whale song or human music). However, perhaps surprisingly, the status of birdsong as an adaptation in the traditional historical sense (Reeve \& Sherman, 1993; West-Eberhard, 1992; Williams, 1966) remains unclear. The reason is that neither song itself, nor the organs producing it, fossilize, so we have very little to go on in terms of documenting its past history. Furthermore, the current utility of song appears to be quite labile, even within species or between closely related species, limiting our ability to reconstruct common ancestors to the relatively recent past. Thus, although it is widely agreed that sexual selection played a role in the evolution of passerine song, there is little specific discussion of the past function(s) of birdsong in the literature, nor is there likely to be. See (Kroodsma \& Byers, 1991) for a more detailed discussion, and (Catchpole \& Slater, 1995) for more examples.

The traditionally given functions of male birdsong are two: territorial defense and mate attraction/courtship (Catchpole \& Slater, 1995). The first of these has been rigorously tested in a few passerine species. There are two key types of evidence. In the first, a male is removed from his territory and replaced by a loudspeaker broadcasting his song. Such studies have demonstrated that territories without broadcast song 


\section{ARTICLE IN PRESS}

are invaded more rapidly by other males than those where song is played (e.g., Falls, 1988). However, since the comparison is between song and silence, these experiments have typically left uncertain whether any male vocalizations (e.g., calls) might be equally effective (Kroodsma \& Byers, 1991). The most convincing demonstrations thus come from selective muting experiments. A tiny puncture in the air sac surrounding the syrinx in sparrows allowed the birds to produce normal calls, but rendered them incapable of producing full song (McDonald, 1989). These songless males were both delayed in obtaining, and deficient in retaining, territories. Such disadvantages are reversed when the muted males regain their singing abilities (Smith, 1979). Taken together, speaker replacement and muting studies provide quite convincing evidence of the current utility of song in territorial defense in some songbird species. Territorial defense is also the most often cited potential function of female bird song (Langmore, 1998, 2000).

The utility of birdsong for attracting and stimulating females is somewhat less convincing (Searcy \& Yasukawa, 1996). Various studies have shown that more females are trapped at nest boxes with loudspeakers broadcasting song than with silent loudspeakers, but not that song is more effective than other vocalizations in this context. In one abstract, males were reported to be equally attracted as females, raising the possibility that the advantages of advertisement (attracting a mate) might be outweighed by the costs (attracting a rival). Indeed, males of some songbird species stop singing once a female arrives, suggesting that such tradeoffs may be significant. The evidence that male song stimulates females includes correlational studies showing male song peaking at the time of egg laying (Logan, 1983) - but who is stimulating who in this situation? Song played from a loudspeaker increases female nestbuilding activity in several species (e.g., Hinde \& Steel, 1976), with more complex songs being more effective (Okanoya, 2004). In contrast to this evidence concerning the effect of male song on females, I know of no evidence showing that female birdsong functions to stimulate or attract males. However, the role of duetting by a mated pair has been hypothesized to help cement and maintain the pair bond in some bird species, and thus is potentially a sexually selected trait (Langmore, 1998; Todt \& Hultsch, 1982; Wickler, 1980).

Beyond these demonstrations of particular current utility of birdsong there are a number of more speculative hypotheses that are plausible (e.g., song as a group "password" (Feekes, 1982), for social cementing (Hausberger, Richard-Yris, Henry, Lepage, \& Schmidt, 1995), or for family bonding (Ritchison, 1983)). Furthermore, "song" per se is not necessarily a valid unitary category in some species, which have multiple song types involved in mating vs. territoriality (Morse, 1970), and there can be overlap in the function of songs and calls (Marler \& Slabbekoorn, 2004). Thus, it is better to speak of the functions of birdsong (Kroodsma \& Byers, 1991), recognizing that some of these might be sexually selected, while others (like female territorial song that repels conspecifics of both sexes) are better seen as products of recent natural selection. Furthermore, vocal learning as a capacity underlying song has evolved in animals in several instances where sexual selection plays no obvious current role (e.g., in dolphins and other toothed whales, and perhaps parrots (Janik \& Slater, 1997)). Thus, the comparative data 


\section{ARTICLE IN PRESS}

suggest multiple possible selective routes to song, and sexual selection must not be simply assumed as the only possibility.

In conclusion, in contrast to the current utility data just discussed, data on past function that could inform models of birdsong evolution are scarce, and may remain so in principle. Although most biologists assume that birdsong is an adaptation (in a relatively weak and unspecified sense), there is little basis for any specific hypotheses that would justify terming it an adaptation in the stronger historical sense (a laWilliams, 1966). It is important to note that is no impediment to the biological study of birdsong, which is clearly one of the most advanced areas in the study of animal communication (Hauser, 1996). These data have two implications for biomusicology. First, although we can readily study the current utility of music in human cultures, suppositions about its past function(s) will be extremely hard to test. Second, the existence and function(s) of female song in birds suggest that caution is required in extrapolating from male-biased birdsong to sexually egalitarian human singing.

\subsubsection{Parallels between birdsong, language and music}

There are many number of intriguing parallels, at mechanistic, behavioural and formal levels, between birdsong, spoken language and music (cf. Doupe \& Kuhl, 1999; Fitch, 2000; Marler, 1976; Nottebohm, 1976). Perhaps surprisingly, the parallels with language have received far more attention (Marler, 2000). The most obvious shared trait is that all three are learned. Recent progress in understanding the neurobiology of birdsong suggests that, despite major differences in brain anatomy, shared mechanisms may underlie vocal learning in birds and humans (Jarvis, 2004; Nottebohm, 1999). Most impressively, the recent rediscovery of neurogenesis in adult mammals followed directly from the demonstration of song-related neurogenesis in birds (Nottebohm, 1989). Early events in song learning include the expression of genes that are shared by birds and mammals, which are likely to play a role in language and song learning in humans as well (Haesler et al., 2004; Jarvis \& Nottebohm, 1997; Teramitsu, Kudo, London, Geschwind, \& White, 2004; Webb \& Zhang, 2005). At the behavioural level, song-learning birds go through a "sensitive period" early in life, when they must be exposed to normal conspecific song if they are to develop normal singing behaviour (Marler, 1987), paralleling the critical or sensitive periods documented for some aspects of language and music learning in humans (Newport, 1991; Trainor, 2005). Perhaps related, birds with vocal learning go through an immature stage where they produce highly variable song, termed "subsong", which develops towards an accurate rendition of their tutors' song during a process of successive experimentation and approximation (Doupe \& Kuhl, 1999; Tchernichovski, Mitra, Lints, \& Nottebohm, 2001). This process, which creates a self-stimulatory auditory/motor loop, has been shown in a few species to be necessary for adequate song learning (cf. Marler \& Slabbekoorn, 2004), and appears analogous to human infant babbling (Oller \& Eilers, 1988; Vihman, 1986). The hypothesis that a babbling stage is a necessary ontogenetic component of the complex vocal learning underlying song in all species could be tested by tracking song development in vocally learning species, such as humpback whales or seals, in which ontogeny is not yet understood. 


\section{ARTICLE IN PRESS}

At a formal level, there are several clear analogues between birdsong and human music and/or linguistic phonology (Marler, 2000). The first is that the generative process by which individual male birds, in many species, create a unique song involves the recombination of learned or innate notes (individual vocal units shared by all members of the species) into more complex syllables and songs that are differentiated by which notes are selected and the order in which they are arranged. Marler terms this generative process, by which a small number of notes is arranged into a large number of songs, "phonocoding" (Marler, 1970a; Marler, 2000), and observes that this is the same principle by which a large number of words or songs are generated from a small number of syllables or notes in language and music [sometimes termed the "particulate principle" (Merker, 2002; Studdert-Kennedy \& Goldstein, 2003)]. Second, there are often several levels at which this recombination can occur; giving birdsong a multi-level or hierarchical organization similar to that observed in human phonology (note that this is NOT tantamount to recursion in linguistic syntax, which involves self-embedded hierarchy). Interestingly, in at least some bird species (e.g., some sparrows), the hierarchical generation of such phrase structure appears to be rule-governed (i.e., some theoretically possible permutations are never observed), and these constraints or rules are shared by all members of the species (Marler, 1984). A final formal similarity between learned bird song (and other animal songs such as whale song) and human speech and music is the existence of historical change in vocal signals and geographical ("dialectal") variation between populations of the same species. The study of the historical process of transmission and change in human vocal traditions (Hock, 1989; Labov, 1994) may offer a valuable model for similar analysis of dialectal change in bird song (Lachlan, 1999).

This brief summary of formal similarities between birdsong and music does not exhaust the list, and many other possible parallels have not yet been subjected to empirical study (for a long and somewhat speculative list see Hartshorne, 1973). For instance some birds produce a pattern of notes, but repeatedly change the base frequency on which the pattern is based, a process reminiscent of transposition or key modulation in human music (e.g., the hermit thrush Catharus guttatus (Rivers \& Kroodsma, 2000; Wing, 1951)). While most birds use glides and other variable-frequency notes in their song, some birds produce fixed-pitches with scale relations strikingly similar to those used by humans (e.g., the musician wren Cyphorhinus ara$d u s$ ). The details of phrase structure in birds with complex songs (e.g., mockingbirds Mimus polyglottos) are only beginning to yield to study (Thompson et al., 2000), and the possibility of long-distance regularities or "rhyme", like those observable in whale song (see below) has not to my knowledge been investigated. Finally, the basis on which listeners evaluate songs, what might be thought of as an incipient field of "birdsong aesthetics", can be empirically evaluated via female choice experiments comparing different songs (e.g., Catchpole, 1980).

Summarizing, the learned, complex vocalizations constituting birdsong have been subjected to rigorous study of mechanism and function, and we know more about the biology and evolution of birdsong than for any other animal signaling system. Although frequently produced by males, birdsong is also produced by females, both solo and in duets, in many species. Rigorous experimentation has allowed empirical 


\section{ARTICLE IN PRESS}

demonstrations of the current utility (immediate adaptive function) of birdsong in several species, with clear demonstrations of its utility in territoriality and indications of its role in courtship available (this cannot be said of music in any other species, including humans). There is increasing appreciation of the frequency of female bird song, but little work to date on its mechanisms and function. Solo song by females birds appears to function in territoriality, and duets may have both territorial and pair-bonding functions, suggesting caution when extrapolating from male birdsong to human music. Several robust behavioural and formal similarities between birdsong and human music have been identified, and many more hypothesized, and further empirical study of such parallels may yield rich insights into the biological basis of human music. Indeed, although the similarities between birdsong and human speech have been noted for many years, the analogy to human music seems much more fitting.

\subsection{Whale song}

Whales or cetaceans are divided into two large groups: the baleen whales (Mysticetes) and the toothed whales (Odontocetes). The odontocetes include small forms like the $1 \mathrm{~m}$ harbour porpoise, well-known species like bottlenosed dolphins, killer whales, and the sperm whale, the largest odontocete. Although vocal learning has been clearly documented in this group (Janik \& Slater, 1997), none of the toothed whales have complex vocalizations that have been termed song (though both sperm whale codas, Watkins \& Schevill, 1977) and some bottlenosed dolphin phrases (Dreher \& Evans, 1964) might potentially justify the use of this term. The term "song" has traditionally been reserved for the long, complex vocalizations of baleen whales, especially the humpback whale Megaptera novaeangliae, as well as related species such as the bowhead whale Balaena mysticetus. In this brief review, I will only discuss the first species, which is by far the best studied. Males of some other baleen whale species (e.g., fin whales) also make loud, low-frequency vocalizations (Clark, Borsani, \& Notarbartolo-di-Sciara, 2002) that are believed to be involved in courtship or mating, but are not complex enough to have earned the name "song".

Humpback whales are found in all the world's oceans, migrating between high latitudes (either arctic or antarctic) where they feed, to tropical waters where they give birth and mate (Hoelzel, 2002). Although song is mainly concentrated during the mating season, and believed to be produced only by males, some singing is occasionally heard during migration, or at the summer feeding grounds (Clark \& Clapham, 2004). Although songlike underwater sounds had been known by oceanographers for many years (and indeed, it has been suggested that singing Mediterranean humpbacks are the origin of the Greek myth of sirens singing) these vocalizations were not definitively linked to whales until the 1960s (Payne \& McVay, 1971). Although humpback whale song has been intensively studied since this time, our understanding of the biology of whale song lags far behind the study of birdsong, partly for this historical reason, and partly for purely practical reasons (humpback whales cannot be raised in the laboratory, and oceanic field conditions limit observation and experimentation). Nonetheless, three decades of research have revealed some fascinating 


\section{ARTICLE IN PRESS}

formal and "cultural" aspects of these complex and beautiful vocalizations (Payne, 2000).

Humpback whale song has a prominent hierarchical structure, with individual notes or "units" (150-8000 ms) combined into subphrases and phrases (around $15 \mathrm{~s}$ long). Phrases may be repeated or combined to form "themes" (around $2 \mathrm{~min}$ long). Finally, a "song" consists of 10 or fewer themes, and lasts around $12 \mathrm{~min}$, and may be sung nearly continuously, forming "song cycles" that continue for hours (the longest ever recorded was $21 \mathrm{~h}$, (Payne, 2000)). The song cycles show geographical or "dialectal" variation: the humpback song in Hawaii is quite different from that in Australia, and that in the Caribbean quite different from that in the Mediterranean at any point in time. But songs at each specific population are also rapidly changing, with the peak of change coinciding with the peak of singing in the breeding season. Intriguingly, there is cultural transmission of the songs in any locale, such that all male whales sing the "same" songs (though perhaps differently arranged, and with minor individual differences) during any period. However, each individual whale sings independently, and there is no evidence of synchronous chorusing, call and response synchronization, or other similar phenomena. The fact that songs from the end of one breeding season are resumed at the beginning of the next season, essentially unchanged, argues against this relatively rapid change of the song resulting simply from copying errors or loss of memory, instead suggesting that there is an active creative process of change in a given population's song. Of course, such cultural change is also typical of human musical styles, and of language, though typically at a slower rate.

Katherine Payne has suggested that the continual change in humpback song and the need to conform to the singing of the rest of the population conspire to make considerable demands on a singing whale's memory (Payne, 2000). This provides a possible reason for the apparent hierarchical structure in whale song: hierarchy allows cognitive "chunking" and thus makes long complex sequences easier to remember (Simon, 1962, 1972). Extending this idea, Payne and colleagues suggest that the consistent repetition of certain units at the beginning or end of phrases might represent a form of "rhyme" that enables easier recall (Guinee \& Payne, 1988), paralleling a function of rhyme in traditional human oral traditions. Thus the existence of hierarchical phrase structure, the clear and rapid cultural change in song details, and the possible existence of rhyme in humpback whale song all offer clear parallels to formal aspects of human song, and whale song represents one of the best-documented cases of cultural change in non-human animal vocalizations.

\subsection{Seal song}

The pinnipeds (seals, sea lions, walruses and relatives - the Latin term means "finfooted") are an abundant and highly successful mammal group descended from dog or bear-like carnivores who returned to the sea more recently than cetaceans [25-35 million years ago (Hoelzel, 2002)]. Pinnipeds are more amphibious than cetaceans while all cetaceans give birth in water, all pinnipeds must return to land to give birth, and thus retain some ability to locomote on land. Despite early claims, no pinniped 


\section{ARTICLE IN PRESS}

is known to echolocate. Like cetaceans, however, pinnipeds are relatively large-bodied and large-brained, and vocalizations play a prominent role in their social lives. Two of the three major pinniped groups have independently evolved vocalizations complex enough to be termed song - the phocid seals ("earless" seals) and the walrus. Otariid or "eared" seals (sea lions and fur seals) are highly vocal, but none of their varied barks, coughs, snorts, puffs, roars and screams have been elaborated into more complex vocalizations. Walrus vocalizations have been described as clicks, rasps, grunts and a remarkable bell-like tone associated with sexual activity, made only by males, which have a peculiar pharyngeal pouch that is responsible for its production (Fay, 1960). The bell tone is often preceded by stereotyped click sequences into a vocal display termed "song" by (Ray \& Watkins, 1975), but walrus song is only now beginning to receive intense study (Sjare, Stirling, \& Spencer, 2003).

Phocid seal vocalizations are the best studied pinniped songs. Phocids are better adapted to aquatic existence than otariid seals, and mating generally takes place underwater (Van Parijs, 2003). Most (perhaps all) phocids generate underwater sounds during the mating season thought to be associated with reproduction and territoriality. Some of these are long and complex and traditionally termed "song" (e.g., the long descending trills of bearded seals Erignathus barbatus, or the trills of leopard seals Hydrurga leptonyx which are described as "soft and lyrical" strumming sounds (Thomas \& Golladay, 1996)). Geographical variants or "dialects" have been documented in a number of phocids (Cleator, Stirling, \& Smith, 1989; Thomas \& Golladay, 1996; Thomas \& Stirling, 1983), suggesting vocal learning, and most pinnipeds are easily trained to vocalize on command. However, the only undoubtable evidence of vocal learning comes from an orphaned harbour seal (Phoca vitulina). This seal, named Hoover, was adopted and raised by humans, and learned to convincingly imitate human speech (Ralls, Fiorelli, \& Gish, 1985). Although male harbour seals make long complex underwater vocalizations, underwater bubble blowing, roars, grunts, and creaks (Hanggi \& Schusterman, 1994), these relatively unharmonious vocal displays have not traditionally been termed "songs". But by the definition offered here, which would class these complex, learned vocal displays as "song", harbour seals are clearly another "singing" species.

Although phocids of both sexes are highly vocal, and mother-infant communication makes intensive use of vocalizations in many species (Insley, 2000; McCulloch, Pomeroy, \& Slater, 1999), long complex vocalizations are generally limited to males, and made during the mating season (Van Parijs, 2003). For example, Hoover's speechlike vocalizations peaked in frequency during the mating season and often preceded copulation, suggesting that he was using them as mating displays. Most authors assume that, as with birdsong and whale song, seal song is a reproductive display with functions including mate attraction and courtship, and possibly territorial defense of mating areas. However, because mating generally occurs underwater (and in some cases under ice) in most phocid species, there is little concrete or experimental evidence to back up this assumption at present. I know of no work evaluating female seal's response to playbacks of seal song. In summary, we know far less about seal singing than about whale or birdsong, though research interest is growing. Because seals can easily be kept in captivity, we can be hopeful for more information 


\section{ARTICLE IN PRESS}

and perhaps experimental work in the near future. Research on seal song is particularly relevant because seals may be the only species other than humans that use the phylogenetically ancient laryngeal vocal production system of vertebrates in song: birds and odontocetes have evolved novel sound producing organs, and sound production in baleen whales is not understood.

\subsection{Instrumental music: Great ape drumming}

The examples of animal song discussed have all clearly evolved independently of human musical abilities: neither our last common ancestor with birds, nor that with aquatic mammals, would have been a singing species. As previously emphasized, no non-human primate is currently believed to learn complex vocalizations, and indeed the abilities of non-human primates to modify or learn their vocalizations are strictly (and surprisingly) limited (Janik \& Slater, 1997; Larson, Sutton, Taylor, \& Lindeman, 1973). Thus, song has evolved convergently in a number of independent lineages, including humans. Although the complex duets of gibbons (termed lesser apes, who are our nearest relatives after the great apes) are complex and sometimes termed "songs", their acoustic structure is not learned but develops reliably in the absence of experience, and the songs of hybrids are intermediate between those of the two parent species (Geissmann, 1984). There is also a vigorous movement component to many of these vocal displays which appears analogous (or homologous?) to human dance, see (Geissmann, 2000). Thus, although gibbon "songs" (and perhaps other primate loud calls) may provide an evolutionary homologue to human music (Geissmann, 2000), they are not song by my definition.

Given this lack of vocal learning, are there any behaviours in our primate cousins that might be related to human music? An interesting behaviour that is both unusual in the animal kingdom and seems relevant to the evolution of music is manual drumming in the African great apes (chimpanzees, bonobos and gorillas), who are our closest cousins. Although there has been surprisingly little study of this behaviour, it is a common component of displays in all three ape species. In gorillas, bimanual drumming in the form of chest beating is a typical accompaniment of male aggressive displays (Geissmann, 2000; Schaller, 1963), and silverbacks sometimes increase the resonance of this drumming display by inflating their remarkable laryngeal sacs (Fitch \& Hauser, 1995) and beating upon them (Schaller, 1963, p. 225). These laryngeal sacs extend into the chest region and overlie the pectoral musculature (Raven, 1950). However, females also produce chest-beating displays, as do immature gorillas, in a more playful context (Schaller, 1963), and sometimes drum on the ground, objects or other gorillas (Fitch and Gomez, unpublished video data). In chimpanzees, drumming is a frequent but not obligatory component of the elaborate vocal/motor dominance displays performed by males (Arcadi et al., 1998; Goodall, 1986). Although the most common drumming surface in nature is tree buttress roots (apparently sought out for their particular loud and resonant quality), chimpanzees will readily adapt to drumming other surfaces including hollow walls ( $\mathrm{J}$ Call, pers. comm.), or overturned buckets (S. Savage-Rumbaugh, pers. comm.). Although drumming bouts in both gorillas and chimpanzees are typically of short duration 


\section{ARTICLE IN PRESS}

(around $1 \mathrm{~s}$ ), bonobos can maintain a steady drummed beat for at least $12 \mathrm{~s}$ (Fitch, unpublished data). However, it is currently unknown whether apes can entrain to an externally generated rhythm, or generate more complex rhythmic patterns than the steady isochronic pulse typically observed. A popular book by Leonard Williams, (who raised monkeys in his home but had no personal experience with apes) dismisses the possibility of ape entrainment, but provides no data in support of this claim (Williams, 1967). There are some intriguing but poorly documented claims for vocal entrainment among gibbons and bonobos (de Waal, 1988; Geissmann, 2000).

Drumming, or instrumental sound generation of any sort, is very uncommon among vertebrates. Perhaps the most striking other example are palm cockatoos, Probosciger aterrimus, which use a stick to strike hollow trees as a communication signal (Wood, 1984, 1988). The only other clear examples are by woodpeckers (who sometimes drum with their bills against particularly resonant trees as displays, in territorial/mate attractions contexts similar to those associated with song in songbirds (Dodenhoff et al., 2001; Stark et al., 1998)). Kangaroo rats and some other desert rodents drum out patterns with their hind feet on the ground (Randall, 1997). But bimanual drumming per se is, as far as I know, unique to the great apes and humans. Drumming is, of course, ubiquitous among world musical cultures, and believed to represent a basic and ancient form of instrumental music (Sachs, 1940). Thus the existence of drumming in the great apes is a clear possible homologue of instrumental music in our own species, one that has previously apparently been overlooked. A more detailed understanding of the contexts of bimanual drumming, and its ontogeny, is extremely desirable as it may provide one of the few direct clues to the evolution of instrumental music in humans.

\section{The phylogenetic history of human music}

As for most behavioural traits, fossil data regarding music are scarce, and data concerning the age of music in our species are limited by the vagaries of archaeological preservation. Regarding singing, which along with bimanual drumming is probably the oldest form of music, we have little to go on (the same situation applies to the evolution of speech and language). However, a rich collection of musical instruments, dating back 35,000 years or beyond (Cross, Zubrow, \& Cowan, 2002; D'Errico et al., 2003), allows us to date instrumental music with much more certainty than language (where only the advent of writing affords indubitable evidence of the advent of language). Below I will discuss one potential anatomical correlate of singing and then briefly survey the archaeological data for instrumental music.

\subsection{Vocal adaptations for song}

Because vocal music does not fossilize, nor do the soft tissue structures of the vocal tract, there is little more to be said about the phylogenetic history and timing of the origins of vocal music than about the evolution of speech (for a concise review 


\section{ARTICLE IN PRESS}

see Fitch, 2000). A recently discovered fossil indicator of a potential change in neural control of vocalization in humans is that modern humans have a larger thoracic vertebral canal than other primates (MacLarnon \& Hewitt, 1999). Because the motor neurons in this region of the spinal cord control some respiratory muscles (intercostals and abdominals, but not the diaphragm as often stated) this enlargement may be linked to greater control over breathing. Because this is a characteristic that can be measured in fossils, this character provides a possible cue to the timing of increased vocal control in the evolution of the human lineage. MacLarnon and Hewitt found that early Homo erectus ( = Homo ergaster) had a similar thoracic vertebral cavity size to chimpanzees or earlier hominids, while Neanderthals resemble modern humans, and concluded that increased breathing control occurred no earlier than late $H$. erectus.

Although the authors considered these data in the context of the evolution of speech, the changes they have documented are equally, if not more, relevant to song (Fitch, 2006). Johan Sundberg has convincingly argued that singing requires finer respiratory control than that necessary for speech (Sundberg, 1987). In normal conversational speech, the rate of airflow is around $0.2 \mathrm{~L} / \mathrm{s}(0.1-0.3 \mathrm{~L} / \mathrm{s})$ and approximately $2 \mathrm{~L}$ tidal volume are utilized. With no involvement of the intercostals, and simple passive lung deflation, this would give $10 \mathrm{~s}$ of normal speech. But speakers normally breathe every $5 \mathrm{~s}$. In contrast, phrases over $10 \mathrm{~s}$ are common in song, and singers often use nearly all of their approximately $5 \mathrm{~L}$ vital capacity. Furthermore, much greater subglottal pressures are generated during singing than speech $(6-70 \mathrm{~cm}$ water relative to $6-15 \mathrm{~cm}$ water in normal speech). Most importantly, the finer control over amplitude and pitch required in singing requires singers to use all major respiratory muscles (including both sets of intercostals, the diaphragm, and the abdominal muscles), while speech typically requires the use of only one set of intercostals for compensatory maneuvers. Thus, an increase in fine respiratory control would seem to be more important in singing (where maintaining a constant and accurately controlled subglottal pressure for consistent amplitude and pitch is a necessity, in modern practice) than for speech (where pitch is in any case varying continuously over a wide range). These data are thus consistent with the hypothesis that song evolved either before, or simultaneously, with speech.

\subsection{Instrumental music: Archaeological data}

Regarding instrumental music we are more fortunate than for fossil evidence of song. A relatively rich archaeological record of musical instruments has been preserved, including uncontested flutes associated with anatomically modern humans at least 36,000 years old (Cross et al., 2002; D'Errico et al., 2003). The most abundant archaeological musical instruments are flutes, of which hundreds have been recovered, reviewed by (Scothern, 1992). At least 17 bone flutes (or flutelike objects) have been recovered from a site called Isturitz in the Pyrennees (aged are around 20,000 years). The oldest uncontested bone flutes are a pair, made from wing bones of a swan, from Geissenklösterle in Germa- 


\section{ARTICLE IN PRESS}

ny, dated to $36,800 \pm 1000$ years ago. The more intact of these has three holes still intact, with 3-4 cm spacing (Hahn \& Münzel, 1995). In addition to these artifacts, which are clearly musical instruments, a number of other artifacts that are plausibly instruments have been recovered, including bullroarers (Dauvois, 1989), rasps (a percussion instrument like a guiro) (Huyge, 1990), and a mammoth-bone marimba-like percussion instrument (Bibikov, 1978). Naturally occurring stone formations ("lithophones") also show signs of having been used as percussion instruments (Cross et al., 2002; Dams, 1985). Thus it is widely agreed, based on unambiguous bone flutes, that instrumental music dates back at least 36,000 years, which is thus a firm minimum age for instrumental music in our species. However it is important to note that bone flutes are quite unusual among living human cultures, with reed or wood flutes and pipes much more common. It is much harder to bore holes in bone than in hollow sticks or reeds, and we can say with virtual certainty that flutes made of materials that are not preserved predated the known exemplars, perhaps by many thousands of years. It is also likely that a host of other instruments such as drums and rattles, that are ubiquitous today in all the world's cultures but made of perishable materials, coexisted with or predated these preserved artifacts. Thus instrumental music is at least 36,000 years old, but is almost certainly older, perhaps much older. As a rough figure, we can thus take 40,000 years as the minimum age of human music.

More controversial is a Neanderthal "flute", which although not much older, would push the evolution of instrumental music back to the common ancestor of Neanderthals and anatomically modern humans. However, there has been considerable debate, still unresolved, about whether this artifact is properly considered a flute (Kunej \& Turk, 2000). This Divje Baba find is a fossilized cave bear bone artifact with two clear preserved holes, and three further damaged potential holes, considered by its discoverers to be a Neanderthal flute (Kunej \& Turk, 2000; Turk, 1997). This object has been unambiguously radiocarbon-dated to $43,100 \pm 700$ years of age (Nelson, 1997). The artifact was discovered in a Slovenian cave, accompanied by Mousterian tools indicative of simultaneous Neanderthal habitation. Although the date is only a few thousand years older than Geissenklösterle, if the object really is a flute made by Neanderthals it would date the origins of instrumental music to the common ancestor of Neanderthals and anatomically modern Homo sapiens - often equated with Homo heidelbergensis or H. antecessor (Boyd \& Silk, 2000) - and estimated to have split around 500,000 years ago (Krings et al., 1997). Although archaeological data for determining the age of spoken language are, as already mentioned, very controversial, this predates the onset of full spoken language posited by many scientists, and as suggested by new genetic data (Enard et al., 2002). Unfortunately, the artifact has been damaged by chewing by a carnivore, and skeptics have suggested that the holes remaining were punctures made by carnivore teeth (D'Errico, Villa, Llona, \& Idarraga, 1998). Although experiments reported in (Kunej \& Turk, 2000) seem inconsistent with that conclusion, and debate continues, it seems prudent to maintain a certain amount of circumspection at present. 


\section{ARTICLE IN PRESS}

\subsection{Music as protolanguage}

As emphasized above, the material evidence concerning the past history of human musical abilities is largely limited to instrumental music, and almost certainly underestimates the age of song. Several lines of evidence lead to the hypothesis that an areferential songlike communication system predated language in human evolutionary history. This hypothesis was first stated clearly by Darwin (1871), and has since been restated or re-discovered by many others (Livingstone, 1973; Marler, 2000; Merker, 2000, 2002; Mithen, 2005; Richman, 1993) often without attribution (e.g., Brown, 2000). Darwin suggested that a primitive song-like communication system represented a precursor of human language that was adaptive "for the progenitors of man" and that modern music exists as a sort of behavioural fossil of this past system. By this hypothesis, humans have gone through at least one pre-linguistic communication system (or "protolanguage", (Arbib, 2005; Bickerton, 1990; Fitch, 2004)) since our split with chimpanzees and before attaining full modern language. During this five or six million years of evolution, different selective regimes might well have driven different components of the contemporary language faculty.

Darwin's hypothesis of a shared ancestral precursor of music and language is elegant in that it acknowledges the many shared features of music and language (both in the realms of formal structure and in terms of mechanisms, such as vocal learning), but also leaves room for the evolution of their differences (particularly semantics in language) in a simple phylogenetic sequence. It also jibes with the greater individual variability (Judd, 1988; Sloboda, 1985) in music-making skills today (which are, by hypothesis, no longer as strongly selected) relative to language skills (currently under powerful positive selection). From the comparative perspective, we have abundant evidence that music-like communication systems can evolve relatively easily (at least three times among birds and three times in mammals), while a complex communication system with the ability to communicate arbitrary meanings has evolved only once, in humans (Hauser et al., 2002; Marler, 2000). This makes a hypothesis in which complex signals ("song") evolved first, and that meanings were added to these signals later (e.g., Wray, 2002) quite parsimonious from a comparative viewpoint. For further discussion, see (Fitch, 2004; Fitch, 2005; Mithen, 2005).

Darwin himself focused mainly on speech and song, with little said about instrumental music or dance as musical systems, or sign as an alternative output mechanism for language. However, given our modern understanding that signed languages are full human languages, an updating of his theory to include complex, rhythmic movement/gestural patterns (dance as "protosign") would be straightforward. Of course, to the extent that the musical protolanguage hypothesis is valid, it makes the question of music's current utility moot: by this hypothesis protomusic might once have had specific functions (courtship and/or territioriality) but exist today as only a remnant, the critical functionality having been replaced by language in modern humans. Thus, the musical protolanguage hypothesis raises additional concerns about our ability to resolve adaptive questions about musical behaviour in our species, even more so than for other cognitive traits like language (Fitch, Hauser, \& Chomsky, 2005). I will close with a brief consideration of this issue. 


\section{ARTICLE IN PRESS}

\section{The function(s) of music: Music as an adaptation}

What, if any, adaptive functions does music serve? Put more precisely, why did those of our ancestors who possessed and expressed musical skills out-reproduce those who did not? The situation was precisely summarized by Darwin, who concludes: "As neither the enjoyment nor the capacity of producing musical notes are faculties of the least use to man in reference to his daily habits of life, they must be ranked amongst the most mysterious with which he is endowed" (Darwin, 1871). Some commentators see this question as being central to the biology and evolution of language (Balter, 2004; Huron, 2001), and since Darwin posed the question, few stones have been left unturned as to potential functions of music. This older literature is reviewed by (Révész, 1941; Roederer, 1984), and a brief synopsis given in English by (Kunst, 1959). Below, I will address the function(s) of music first from a relatively traditional evolutionary viewpoint, in the context of natural, sexual and kin selection (including what is sometimes called group selection). These different categories of selection are not fundamentally distinct: selection acts by changing gene frequencies in populations over time, and is ultimately blind to the reasons for which these changes occur. However, conceptual partitions of this sort can be useful for clarifying hypotheses and driving empirical predictions, and thus can have heuristic value (cf. Frank, 1998).

\subsection{Music as a spandrel}

One clear possibility to address first is the null hypothesis that music has no adaptive function at all. As stressed by (Williams, 1966) in his foundational work, adaptation is an "onerous concept" to be demonstrated, not assumed. Despite the caricature of "Panglossian adaptationists" painted by Gould and Lewontin (1979), evolutionary biologists since Darwin have recognized that there are always some traits in any species that are non-adaptive (the vestigial appendix of humans being one classic example). Similarly, one answer to Darwin's quandary about the value of music may be that music is a byproduct of some other capacity such as language, but is not specifically adaptive in itself. Such traits have been dubbed "spandrels" (Gould \& Lewontin, 1979), borrowing an architectural term for a necessary but non-functional concomitant of a primary load-bearing function. Given the negative character of this hypothesis, if musical is a spandrel, the fastest way to find out is by positing adaptive hypotheses and then rejecting them one by one. As the review below will make clear, we are still not in a position to do that convincingly for music. Thus, the "music as spandrel" hypothesis stands as an important challenge to be met by scientists interested in demonstrating adaptive function(s) for music.

A related possibility is that music is a recent technological innovation designed by humans to "push our pleasure buttons" - the "music as cheesecake" hypothesis (Pinker, 1997). The strongest arguments against the cheesecake hypothesis are its age (at least 40,000 years) and the sheer quantity of musical behaviour that humans produce (Huron, 2001). Unlike cheesecake, music and dance are found in all cultures, and have been for many thousands of years. Music is loud (attracting attention 


\section{ARTICLE IN PRESS}

of predators or enemies) and energetically expensive (sometimes to the point of exhaustion), and if music had no value whatsoever, one might expect strong selection against musical behaviour. Recent evidence for congenital amusia - non-musical humans - indicates that the necessary genetic variance is present in human populations (Peretz \& Hyde, 2003). So why have not quiet, better-rested non-musical humans out-reproduced and replaced their musical conspecifics? Thus, the ubiquity and age of music are hard to square with the cheesecake hypothesis, even accepting the conservative and minimal age of 40,000 years, and particularly if we can interpret the fossil evidence as indicating that music predates the modern human/Neanderthal split.

The spandrel hypothesis, specifically the idea that music is a byproduct of selection for the mechanisms underlying language, is more difficult to refute. If music results automatically from linguistic mechanisms, then powerful selection for language could swamp weaker selection against music. Here, the best data will come from detailed consideration of the formal similarities and differences between language and music (see Jackendoff \& Lerdahl, in press) and analysis of the neural mechanisms underlying the two (Avanzini et al., 2003; Peretz \& Zatorre, 2003). A long history of dissociation between aphasia and amusia from the clinical neurology suggested that there are differences in the ways music and language are implemented by the brain, and modern brain imaging work has partially confirmed this finding. To the extent that music really requires a different suite of mechanisms from language, this is prima facie evidence against its being a spandrel of language (Peretz \& Hyde, 2003; Peretz \& Zatorre, 2005) but the considerable overlap between brain regions involved in musical and lingustic tasks currently offers no clear verdict on this question at present (Koelsch et al., 2002, 2004; Patel, 2003; Peretz \& Zatorre, 2003). Another approach is to seek evidence that musical and linguistic skills are dissociated among individuals in a population, and that these differences have a genetic basis. Such data currently offer the clearest path to demonstrating a separate faculty of music that would justify rejecting the spandrel hypothesis.

\subsection{Sexual selection}

One often cited function of music, prominent both in the scientific literature and in the popular press, is in sexual selection, specifically mate choice. The function of music in human courtship has considerable intuitive appeal, along with a long literary tradition. That music has powerful and essentially involuntary effects on mood, arousal and emotion (e.g., Husain, Thompson, \& Schellenberg, 2002; Juslin \& Sloboda, 2001) speaks in its favour, as does some data on birdsong and whale song. This was one component of Darwin's (1871) hypothesis for song evolution, concluding by analogy with bird song and other animal signals that proto-human song "would have been especially exerted during the courtship of the sexes, - would have expressed various emotions, such as love, jealousy, triumph, - and would have served as a challenge to rivals". Thus, Darwin answers his question of the function of song by analogy with a wide variety of other curious sexually selected traits of animals, from peacocks' tails to deer antlers to birdsong. 


\section{ARTICLE IN PRESS}

This hypothesis remains popular today, and has been reviewed recently by (Miller, 2000, 2001), but the case remains unconvincing at present. That great musicians sometimes have many sex partners seems indubitable. However, there is a surprising lack of data testing, much less supporting, this idea, so skepticism is necessary. For every Bach with many children there may be a Beethoven who died childless, and for every popular conductor or lead guitarist there may be a lonely oboist or bassist. In some cultures, musicians occupy a relatively low-ranking class or caste, and the itinerant lifestyle of the griot may not be ideal for fathering and raising children. I know of no data, in any culture, that demonstrates that musicians have higher RS (reproductive success) than non-musicians. Of course, absence of evidence is not evidence of absence, but if there is a strong effect, it should be relatively easy to demonstrate, making this lack of evidence puzzling. In Miller's defense, most traditional cultures' musics are inclusive, with no distinction between audience and performer, and thus everyone can be judged on the basis of their singing, rhythm or dance. Thus, as (Miller, 2000) argues, music may provide one means for a choosy mate to choose well. However, we should be careful about extrapolating from mating success in western populations to RS, since mating success is a poor proxy for RS in post-birthcontrol cultures. A woman choosing a one-night-fling with an itinerant musician today might have made quite different decisions knowing she might become pregnant with a bastard son in earlier times or other cultures. Thus actual RS data from more traditional cultures would be the most convincing.

A richer source of evidence is the comparative data reviewed above. In birds, where sexual selection for song is most clear, it is mostly males that sing, and this is also the case in whales and seals. This is definitely not the case in humans, where women sing in most cultures, and male and female musical abilities do not clearly differ. Although instrumental music may traditionally represent a male-biased behaviour (e.g., the all-male symphony orchestra; or some traditional cultures where women are forbidden to even touch drums or other sacred instruments) (for further discussion see Miller, 2000). However, such numerical differences appear to stem more from cultural power relations rather than innate dimorphism: the rapid rise of excellent female instrumentalists once cultural prohibitions are lifted speaks against any truly biological differences in instrumental ability. Thus, as for language (Hyde \& Linn, 1988), musical abilities show a remarkably egalitarian sexual distribution pattern. This is a serious problem for the hypothesis that sexual selection was the major driving force in music evolution, certainly for song and probably instrumental music as well. A caveat is in order, however, based on the increasing evidence for song in female birds discussed earlier. Although the bias towards male song is huge, and uncontested, female birds do sing in many species, and these uses often seem to involve territorial function rather than mate choice (Langmore, 2000).

In summary, the evidence supporting a mate-choice function for human music is unconvincing at present despite the intuitive appeal of this hypothesis (at least to musicians) Fortunately, this data-poor situation need not persist, considering how easily available relevant data should be (e.g., carefully designed web-based questionnaires or detailed historical data for musicians would provide a good start). Thus I join (Miller, 2000) in calling for more empirical attention to this hypothesis, stressing 


\section{ARTICLE IN PRESS}

the value, in this case, of publishing null results. Careful experiments finding no difference in musicians' RS (or among male and female musical abilities) would be quite important. But based on current data, the assumption that music is a sexually selected trait complex is unjustified.

\subsection{Kin (and group) selection}

\subsubsection{Group functions of music}

In our society music often seems to bind social groups together: ritual song, children's play songs, and parties with dancing and music can defuse tension and encourage peaceful and cooperative interactions. Furthermore, a group engaged in vigorous coordinated musical and dance behaviour is an impressive spectacle that might plausibly dissuade potential outside aggression. This has led many to suppose that music functions in "group cohesion" (cf. Miller, 2000). For example, Cross has suggested that music represents a form of play that both aids child development and decreases tension within groups (Cross, 2003). In the context of the weaknesses of sexual hypotheses described above, and the recent upsurge of interest in multi-level selection, it seems likely that such socially oriented hypotheses will increase in popularity. However, it is important to separate a discussion of group functions from that of group selection. The topic of group selection is a tricky one in evolutionary theory, and its fortunes have oscillated wildly since Darwin (Sober \& Wilson, 1998). Although no one doubts the theoretical possibility of group selection, its strength and prevalence have been much debated. A major advance in modern evolutionary theory was the observation that individual selection will be stronger in the vast majority of situations, such that in situations of conflict between group and individual selection the latter will generally dominate (Maynard Smith, 1964). This fact argued strongly against the then-prevalent logic that individuals will sacrifice themselves "for the good of the species" and thus once again highlighted the problem of "altruistic" animal behaviour that had troubled Darwin considerably. This clarification led to the most important advance in evolutionary theory since Darwin: Hamilton's theory of inclusive fitness (Hamilton, 1964), which led quickly to the flowering of kin selection theory as an explanation for "altruistic" behaviour in animals. The realization that groups are often made up of closely related kin allows many of the observations once considered to be "for the good of the group" to be recast in individualistic (or nepotistic) terms. Individuals are sometimes nice to others who share their genes, because in doing so they are, in an evolutionary sense, being nice to themselves.

It seems likely that most small groups of humans living together, throughout most of our evolutionary history, were closely related. Although there is always considerable genetic mixture due to outbreeding, the "tribe" throughout most of human history was a large extended family, and humans throughout the world pay very close attention to detailed notions of kinship (not necessarily limited to the biological one) and allocate resources accordingly. Thus, many of the hypotheses arguing for group function in the evolution of music may be recast in terms of kin selection, and inherit a considerable body of theoretical and empirical work as a result. This is not to say that "kin selection" 


\section{ARTICLE IN PRESS}

is valid and "group selection" is not - these are just terms, and there are many ways to partition selection that are potentially equally valid (Frank, 1998). But theorists interested in group functions of music evolution need not accept Miller's assertion that "there's just natural selection and sexual selection - that's it" nor fear that "group selection for music would involve re-writing modern biology" (Miller, 2000). Kin selection provides a viable third path overlooked in Miller's discussion.

Several specific models for functions of song involve groups but are compatible with an individual selection account. For example, Robin Dunbar has proposed that vocal exchanges serve as a sort of "vocal grooming" in humans, replacing the usual one-on-one physical grooming that maintains relationships and is important in the stability of social groups in most non-human primates (Dunbar, 1993; Dunbar, 1996). Dunbar suggested that the increase in group size that seems to have occurred during hominid evolution required a more efficient social lubricant, and that meaningless but complex vocal exchanges filled this role. Although this hypothesis was initially offered in the context of language evolution, it is equally (if not more) relevant in the context of the evolution of song (Dunbar, pers. comm.). Note that, although it invokes the notion of group stability, Dunbar's hypothesis could be driven entirely by individual selection. Another, quite different, hypothesis that involves groups has been developed by Björn Merker, who observed an interesting parallel between mating systems of various chorusing organisms, and the female exogamy characterizing both chimpanzees and many traditional human cultures (where males stay in their natal group at puberty, while females emigrate, reversing the more typical primate trend) (Merker, 1999, 2000). Because amplitude summation means that many voices calling in synchrony carry further than one alone, or many uncoordinated voices, Merker suggests that the origin of humans' unusual entrainment abilities may be found in chorusing groups of males, both repelling rivals and attracting migrating females. Again, this hypothesis posits purely individual gains and does not require group selection.

One fact consistent with the idea that music functions as a kind of "vocal grooming" is that endorphins appear to be released during coordinated group singing (Dunbar, pers. comm.) though this is difficult to test directly. However, it is easy to envision empirical tests of the general hypothesis that shared musical interactions lead to enhanced group cohesion and performance. For instance, one could subject carefully paired groups of children or adults to randomly chosen treatments, where one group creates music together, or dances together, while another plays some nonmusical game (e.g., cards) or watches movies, and then compare group performance subsequent to treatment. By carefully controlling for factors such as simple shared activities, or enjoyment of these activities (e.g., by scoring laughter, or post-treatment interviews), it should be possible to demonstrate a beneficial function of music on group cohesion and performance (e.g., in athletic performance), if there is one. I know of no studies of this sort.

\subsubsection{Mother/infant song}

I now turn to models that explicitly involve kin selection and not simply group function. A particularly clear example of musical behaviour involving close kin is 


\section{ARTICLE IN PRESS}

the use of song between mothers and infants (Dissanayake, 2000), apparently found in all cultures and thus as ubiquitous as music itself (Trehub \& Trainor, 1998). This parallels the equally striking "musical" use of language observed from parents to their young offspring, often termed "motherese" (Falk, 2004; Fernald, 1992). Again, the possibility that such interactions are simply precursors to or side-effects of early language maturation must be borne in mind, as should the fact that the "musical" aspects of motherese and other paralinguistic prosody do not share key design features with music (such as discreteness in frequency and time). However, the clear coexistence of well-formed language simultaneously with non-linguistic song, or nonsense rhymes, suggests at least some independence between these uses. There is surprisingly little research exploring the beneficial effects of this particular type of interaction on infant and child development, but it is abundantly clear that lullaby and other forms of child-directed song provide a widespread and quite effective means of regulating infant arousal (Kneutgen, 1970; Trehub \& Trainor, 1998). The use of lullabies to soothe infants to sleep is apparently a human universal, practiced quite effectively in all cultures (Trehub, 2000). Given the potential detrimental effects of crying or upset infants throughout our evolutionary history, parents' success in achieving this goal could be of considerable adaptive relevance to the evolution of song (Falk, 2004). Similarly, the use of play songs to arouse infants, focus their attention, and strengthen the mother-infant bond is both widespread and potentially adaptively relevant (Trehub, 2003). Thus, the considerable data supporting the effects of music on mood and arousal are compatible with this hypothesis (e.g., Husain et al., 2002; Juslin \& Sloboda, 2001). The extremely early development of music perceptual abilities, while incompatible with sexual selection, is obviously nicely explained by the caregiving hypothesis. A documented infant preference for song over speech provides an argument against the hypothesis that song is simply a non-adapative byproduct of speech (Trehub \& Nakata, 2001). Thus, of all the proposed functions of music, the hypothesis that song plays a role in regulating infant arousal seems to be the most plausible, and to have the best empirical support currently. As before, however, more data are needed for any firm conclusions.

\subsection{Music as play}

As a final example underscoring the difficulty of addressing functional questions with music, consider the proposition that music represents a form of play (e.g., Cross, 2003). The act of making music is described with the verb "to play" in many languages, and both its creative nature and the subjective enjoyment derived by musicians and their audiences suggests that this is an apt word choice (as opposed to, say, "work"). Play in young vertebrates is quite common, and in mammals it is ubiquitous and relatively well-studied (Fagen, 1981). Subsong, the process of variation and selection engaged in young birds as they learn their song, is often considered a form of "vocal play" in birds (Ficken, 1977), as is babbling in human infants. The current leading functional hypothesis for the evolution of play is the intuitive one: that play is a form of practice for behaviours that will be useful for the individual when it attains adulthood (feeding, fleeing, fighting, and mating). Vocal play as a 


\section{ARTICLE IN PRESS}

precursor of adult birdsong is of course perfectly intelligible in these terms, and the ubiquity of subsong in birds suggests that it is not only useful, but perhaps necessary, if an individual is to reliably master a complex vocal repertoire. Similar comments can be made about babbling and language acquisition (Doupe \& Kuhl, 1999).

The idea that music represents a form of mental and/or physical "practice" for other, seemingly unrelated adult skills (e.g., mathematics) is an old one, and is one reason for an emphasis on the value of music in a liberal education. However, contemporary evidence that music listening or performance enhances non-musical skills or intelligence (most recently, concerning the so-called "Mozart effect") remains weak (Steele, Bass, \& Crook, 1999; Thompson et al., 2001). That childhood musical practice is an aid to adult musical excellence is, in contrast, indubitable. But regardless of what music might represent practice for, any adaptive explanation focused on childhood practice for adult competence fails to explain why we continue to see musical behaviour in adults. Of course, humans are unusual in that we retain many behavioural characteristics of juveniles into and throughout adulthood, and play (of all sorts, including music) is prominent among them. It would be a mistake to believe that an adaptive explanation for play (or any other behaviour) must explain all observed instances of that behaviour. If the critical function of vocal song, today and in the past, is as lullabies and play songs for manipulating infant arousal, this would not rule out the continued lulling or energizing effect of such music into adulthood as an unselected byproduct of this function.

As the review above makes clear, the debate surrounding the adaptive function(s) of music has thus far shed considerably more heat than light, and one might reasonably question the value of such debate to our understanding of the biology of music. While I think there are several areas of uncertainty that can be easily cleared up with empirical research, most notably the current utility of music in mother-infant communication, or in courtship and mating, questions about the original function of music seem unlikely ever to be satisfactorily resolved. Thus, while adaptive hypotheses may be valuable spurs to the scientific imagination, as "intuition pumps" leading to testable hypotheses and new insights, they can also easily degenerate into the spinning of tall tales. Given our current knowledge, music (and many other domains of cognition) seem less suited to adaptive hypothesizing than morphologically defined traits (like bipedalism or finches' beaks) (Reeve \& Sherman, 1993). Because the question "is music an adaptation?" is unlikely to receive satisfactory empirical answers, I suggest that the nascent field of biomusicology should not be sidetracked by taking this as its primary research question (e.g., Balter, 2004; Huron, 2001; Roederer, 1984). The field is more likely to make progress by focusing on the many open and empirically resolvable issues than if researchers interested in the biology and evolution of music allow themselves to be preoccupied with questions about past adaptive function.

\section{Conclusions}

Music and language are both human universals, with a bewildering variety of culture-specific forms overlaying deeper but still poorly understood linguistic and musi- 


\section{ARTICLE IN PRESS}

cal universals. Ultimately, the various comparative approaches discussed in this review will be crucial to understanding the biological bases for both of these traits. First, regarding ethnomusicology, the field shows a welcome trend towards overcoming its traditional antipathy to the search for musical universals, and we may hope for considerable progress in outlining the shared core of musical capabilities that are our birthright as human beings (Nettl, 2000). Second, regarding the comparison to language, while studying the biological basis of music and language simultaneously may seem daunting, comparisons should ultimately result in more parsimonious models of human nature. Such models will explain shared features of music and language via common mechanisms at cognitive, neural and ultimately genetic levels, helping us to isolate and understand the remaining differences between these two domains. Thus the study of the biology of human musical abilities will be valuable not only for its own intrinsic interest, but for the light it may shed on the biology and evolution of human language. For example, most humans are musically "enculturated", possessing a basic set of music perception skills that are nearly universal (e.g., Koelsch, Gunter, Friederici, \& Schröger, 2000; Schellenberg \& Trehub, 2003; Trainor, McDonald, \& Alain, 2002), but finer differences in perceptual abilities exist and may have a biological basis (e.g., Drayna, Manichaikul, de Lange, Snieder, \& Spector, 2001; Peretz, Ayotte, Zatorre, Mehler, \& Ahad, 2002). More importantly, the considerable variability in individual music-making capabilities makes music a promising empirical route to understanding the genetic and neural bases of complex, hierarchically structured sensorimotor abilities in humans (Judd, 1988; Sloboda, 1985). Research along these lines has begun to accelerate rapidly in recent years, with no end in sight.

The third arm of a comparative approach to the biology of music, examining the communication systems and displays of other species from the viewpoint of human music, also offers considerable untapped promise. Complex animal vocal communication systems, like bird and whale song, are much more similar to music than to language: signal diversity is generated for its own sake, as in music, rather than to transmit equally complex and diverse messages, as for language (Marler, 2000). Thus, it seems that studies of naturally produced animal communication systems may have more to teach us about the biology and evolution of human music than about language. There has been an explosion of interest in birdsong in recent years, and we know more about birdsong today than virtually any other animal communication system. Major breakthroughs in understanding the functional, behavioural, neural and genetic bases of birdsong are being made yearly. While some aspects of birdsong will obviously be unique to birds, other discoveries (e.g., critical periods, or the role of subsong/babbling) have already revealed deep commonalities in the mechanistic basis for complex vocal behaviour that are shared with humans. Although there are obvious limits on comparable empirical work on whale song, interesting commonalities have already been discovered, and other relevant animal systems like seal song, or ape bimanual drumming, have barely begun to be explored.

These empirical developments, combined with the recent surge of theoretical interest in the biology and evolution of music (Avanzini et al., 2003; Peretz \& Zatorre, 2003; Wallin et al., 2000; Zatorre \& Peretz, 2001) suggest that "biomusicol- 


\section{ARTICLE IN PRESS}

ogy" is a field whose time has come (Zatorre \& Peretz, 2001). Although this field currently has some catching up to do relative to studies of the biology and evolution of language ("biolinguistics"), it may profit by following some of the positive lessons from that related field as well as learning from some of its mistakes (Fitch et al., 2005; Hauser et al., 2002). Positive lessons include the need to break a complex behaviour into independent components, the value of a comparative approach, and the importance of a pluralistic Tinbergian perspective that sees mechanistic, ontogenetic, phylogenetic and functional questions as complementary topics of separate and equal relevance. On the negative side, mistakes to be avoided include the tendency for evolutionary discussions to degenerate into the spinning of untestable "just-so" stories, rather than the generation of testable hypotheses, and a tendency for scholars to engage in ardent defense of a single pet hypothesis, rather than dispassionate surveys of the strengths and weaknesses of multiple hypotheses. To the extent that biomusicology can learn from this history, rather than repeating it, the individual variability in music-making skills, combined with the much richer comparative database, promises rapid empirical progress in our understanding of the biology of music in the coming years.

\section{Acknowledgements}

I thank Peter Slater, Robin Dunbar, Ann MacLarnon, Bruno Nettl, Laurel Trainor and Isabelle Peretz for useful discussions and Jack Bradbury, Ian Cross, Donald Hodges, Marc Hauser, Josh McDermott, Bernie Krause, Björn Merker, Peter Marler, Eric Nicolas, Roger Payne, and an anonymous reviewer for discussion and comments on an earlier version of this manuscript, with the usual absolution regarding my opinions and any remaining errors.

\section{References}

Arbib, M. A. (2005). From monkey-like action recognition to human language: An evolutionary framework for neurolinguistics. Behavioral and Brain Sciences, 28, 105-167.

Arcadi, A. C., Robert, D., \& Mugurusi, F. (2004). A comparison of buttress drumming by male chimpanzees from two populations. Primates, 45, 135-139.

Arcadi, C., Robert, D., \& Boesch, C. (1998). Buttress drumming by wild chimpanzees: temporal patterning, phrase integration into loud calls, and preliminary evidence for individual distinctiveness. Primates, 39, 505-518.

Aristotle. (350 BC). The History of Animals (A.L. Peck, Trans.). London: Heinemann.

Arom, S. (2000). Prologomena to a biomusicology. In N. L. Wallin, B. Merker, \& S. Brown (Eds.), The origins of music (pp. 27-29). Cambridge, Mass: The MIT Press.

Avanzini, G., Faienza, C., Minciacchi, D., Lopez, L., \& Majno, M. (Eds.). (2003). The neurosciences and music. New York: New York Academy of Sciences.

Balter, M. (2004). Seeking the key to music. Science, 306(5699), 1120-1122.

Bibikov, S. (1978). A Stone Age orchestra. In D. E. K. Hunter \& P. Whitten (Eds.), Readings in physical anthropology and archaeology. London: Harper and Row.

Bickerton, D. (1990). Language and species. Chicago, IL: Chicago University Press. 
Bierwisch, M. (1979). Gestische form als bedeutung musikalischer zeichen. Jahrbuch Peters, 1978, 161-178.

Blacking, J. (1976). How musical is man? London: Faber.

Blood, A. J., \& Zatorre, R. J. (2001). Intensely pleasurable responses to music correlate with activity in brain regions implicated in reward and emotion. Proceedings of the National Academy of Sciences United States of America, 98, 11818-11823.

Boyd, R., \& Silk, J. B. (2000). How humans evolved. New York: W. W. Norton.

Brown, S. (2000). The "Musiclanguage" model of music evolution. In N. L. Wallin, B. Merker, \& S. Brown (Eds.), The origins of music (pp. 271-300). Cambridge, Mass: The MIT Press.

Carterette, E. C., \& Kendall, R. (1999). Cross-cultural music perception and cognition. In D. Deutsch (Ed.), The psychology of music (2nd ed., pp. 725-791). New York: Academic Press.

Catchpole, C. K. (1980). Sexual selection and the evolution of complex songs among warblers of the genus Acrocephalus. Behaviour, 46, 300-320.

Catchpole, C. K., \& Slater, P. L. B. (1995). Bird song: themes and variations. New York: Cambridge University Press.

Chase, A. R. (2001). Music discriminations by carp (Cyprinus carpio). Animal Learning \& Behavior, 29(4), 336-353.

Clark, C. W., Borsani, J. F., \& Notarbartolo-di-Sciara, G. (2002). Vocal activity of fin whales, Balaenoptera physalus, in the Ligurian Sea. Marine Mammal Science, 18.

Clark, C. W., \& Clapham, P. J. (2004). Acoustic monitoring on a humpback whale (Megaptera novaeangliae) feeding ground shows continual singing into late spring. Proceedings of the Royal Society B, 271, 1051-1057.

Cleator, H. J., Stirling, I., \& Smith, T. G. (1989). Underwater vocalizations of the bearded seal (Erignathus barbatus). Canadian Journal of Zoology, 67, 1900-1910.

Clynes, M. E. (1977). Sentics: The touch of the emotions. San Francisco, CA: Double Day Anchor.

Clynes, M. E. (1995). Microstructural musical linguistics: Composers' pulses are liked most by the best musicians. Cognition, 55, 269-310.

Croll, D. A., Clark, C. W., Acevedo, A., Tershy, B., Flores, S., \& Gedamke, J. (2002). Bioacoustics: Only male fin whales sing loud songs. Nature, 417, 809.

Cross, I. (2003). Music, cognition, culture and evolution. In I. Peretz \& R. J. Zatorre (Eds.), The cognitive neuroscience of music (pp. 42-56). Oxford: Oxford University Press.

Cross, I., Zubrow, E., \& Cowan, F. (2002). Musical behaviours and the archaeological record: A preliminary study. In J. Mathieu (Ed.), British experimental archaeology (pp. 25-34).

D'Amato, M. R. (1988). A search for tonal pattern perception in cebus monkey: Why monkeys can't hum a tune. Music Perception, 5, 452-480.

D’Errico, F., Henshilwood, C., Lawson, G., Vanhaeren, M., Tillier, A.-M., Soressi, M., et al. (2003). Archaeological evidence for the emergence of language, symbolism, and music - an alternative multidisciplinary perspective. Journal of World Prehistory, 17(1), 1-70.

D'Errico, F., Villa, P., Llona, A. C. P., \& Idarraga, R. R. (1998). A Middle Palaeolithic origin of music. Using cave-bear bone accumulations to assess the Divje Babe I bone 'flute'. Antiquity, 72, 65-76.

Dams, L. (1985). Palaeolithic lithophones: Descriptions and comparisons. Oxford Journal Of Archaeology, 4, 31-46.

Darwin, C. (1871). The descent of man and selection in relation to sex. London: John Murray.

Dauvois, M. (1989). Son et musique paléolithiques. Les Dossiers D'Archéologie, 142, 2-11.

de Waal, F. B. M. (1988). The communicative repertoire of captive bonobos (Pan paniscus), compared to that of chimpanzees. Behaviour, 106, 183-251.

Dissanayake, E. (2000). Antecedents of the temporal arts in early mother-infant interaction. In N. L. Wallin, B. Merker, \& S. Brown (Eds.), The origins of music (pp. 389-410). Cambridge, Mass: The MIT Press.

Dodenhoff, D. J., Stark, R. D., \& Johnson, E. V. (2001). Do woodpecker drums encode information for species recognition? Condor, 103, 143-150.

Doupe, A. J., \& Kuhl, P. K. (1999). Birdsong and human speech: Common themes and mechanisms. Annual Review of Neuroscience, 22, 567-631. 


\section{ARTICLE IN PRESS}

W.T. Fitch / Cognition $x x x$ (2006) $x x x-x x x$

Drayna, D., Manichaikul, A., de Lange, M., Snieder, H., \& Spector, T. (2001). Genetic correlates of musical pitch recognition in humans. Science, 291(5510), 1969-1972.

Dreher, J. J., \& Evans, W. E. (1964). Cetacean communication. In W. N. Tavolga (Ed.), Marine bioacoustics (pp. 373-393). Oxford: Pergamon Press.

Dunbar, R. (1993). Coevolution of neocortical size, group size and language in humans. Behavioral and Brain Sciences, 16, 681-735.

Dunbar, R. (1996). Grooming, gossip and the evolution of language. Cambridge, MA: Harvard University Press.

Enard, W., Przeworski, M., Fisher, S. E., Lai, C. S. L., Wiebe, V., Kitano, T., et al. (2002). Molecular evolution of FOXP2, a gene involved in speech and language. Nature, 418, 869-872.

Fagen, R. (1981). Animal play behavior. New York: Oxford University Press.

Falk, D. (2004). Prelinguistic evolution in early hominins: Whence motherese? Behavioral and Brain Sciences, 27, 450-491.

Falls, J. B. (1988). Does song deter territorial intrusion in white-throated sparrows (Zonotrichia albicollis)? Canadian Journal of Zoology, 66, 206-211.

Farabaugh, S. M. (1982). The ecological and social significance of duetting. In D. S. Kroodsma \& E. H. Miller (Eds.). Acoustic communication in birds (2, pp. 85-124). New York, NY: Academic Press.

Fay, F. H. (1960). Structure and function of the pharyngeal pouches of the walrus (Odobenus rosmarus L.). Mammalia, 24, 361-371.

Feekes, F. (1982). Song mimesis within colonies of Cacicus c. cela (Icteridae: Aves). A colonial password? Zeitschrift Tierpsychology, 58, 119-152.

Fernald, A. (1992). Human maternal vocalizations to infants as biologically relevant signals: An evolutionary perspective. In J. Barkow, L. Cosmides, \& J. Tooby (Eds.), The adapted mind (pp. 391-428). New York, NY: Oxford University Press.

Ficken, M. S. (1977). Avian play. Auk, 94, 573-582.

Fitch, W. T. (2000). The evolution of speech: A comparative review. Trends in Cognitive Sciences, 4(7), 258-267.

Fitch, W. T. (2004). The evolution of language. In M. Gazzaniga (Ed.), The cognitive neurosciences III. Cambridge, MA: MIT Press.

Fitch, W. T. (2005). The evolution of language: A comparative review. Biology and Philosophy, 20, 193-200.

Fitch, W. T. (2006). Production of vocalizations in mammals. In K. Brown (Ed.), Encyclopedia of language and linguistics (2nd ed., Vol. 10, pp. 115-121). Oxford: Elsevier.

Fitch, W. T., \& Hauser, M. D. (1995). Vocal production in nonhuman primates: Acoustics, physiology, and functional constraints on "honest" advertisement. American Journal of Primatology, 37, 191-219.

Fitch, W. T., Hauser, M. D., \& Chomsky, N. (2005). The evolution of the language faculty: Clarifications and implications. Cognition, 97(2), 179-210.

Frank, S. A. (1998). Foundations of social evolution. Princeton: Princeton University Press.

Geissmann, T. (1984). Inheritance of song parameters in the gibbon song analyzed in 2 hybrid gibbons (Hylobates pileatus s H. lar). Folia primatologica, 42, 216-225.

Geissmann, T. (2000). Gibbon song and human music from an evolutionary perspective. In N. Wallin, B. Merker, \& S. Brown (Eds.), The origins of music (pp. 103-123). Cambridge, Mass: The MIT Press.

Goodall, J. (1986). The chimpanzees of gombe: Patterns of behavior. Cambridge, Massachusetts: Harvard University Press.

Gould, S. J. (1991). Exaptation: A crucial tool for evolutionary psychology. Journal of Social Issues, 47, $43-65$.

Gould, S. J., \& Lewontin, R. C. (1979). The spandrels of San Marco and the panglossian paradigm: a critique of the adaptationist programme. Proceedings of the Royal Society B, 205, 581-598.

Gould, S. J., \& Vrba, E. S. (1982). Exaptation - a missing term in the science of form. Paleobiology, 8, 4-15.

Greenewalt, C. H. (1968). Bird song: Acoustics and physiology. Washington: Smithsonian Institution Press.

Guinee, L., \& Payne, K. (1988). Rhyme-like repetition in songs of humpback whales. Ethology, 79, $295-306$. 
Haesler, S., Wada, K., Nshdejan, A., Morrisey, E. E., Lints, T., Jarvis, E. D., et al. (2004). FoxP2 expression in avian vocal learners and non-learners. Journal of Neuroscience, 24, 3164-3175.

Hahn, J., \& Münzel, S. (1995). Knochenflöten aus den Aurignacien des Geissenklösterle bei Blaubeuren, Alb-Donau-Kreis. Fundberichte aus Baden-Würtemberg, 20, 1-12.

Hamilton, W. D. (1964). The evolution of altruistic behavior. American Naturalist, 97, 354-356.

Hanggi, E. B., \& Schusterman, R. J. (1994). Underwater acoustic displays and individual variation in male harbor seals, Phoca vitulina. Animal Behavior, 48, 1275-1283.

Hartshorne, C. (1973). Born to sing. Bloomington, Indiana: Indiana University Press.

Hausberger, M., Richard-Yris, M.-A., Henry, L., Lepage, L., \& Schmidt, I. (1995). Song sharing reflects the social organization in a captive group of European starlings (Sturnus vulgaris). Journal of Comparative Psychology, 109, 222-241.

Hauser, M., Chomsky, N., \& Fitch, W. T. (2002). The language faculty: What is it, who has it, and how did it evolve?. Science 298, 1569-1579.

Hauser, M. D. (1996). The evolution of communication. Cambridge, MA: MIT Press.

Hauser, M. D., \& McDermott, J. (2003). The evolution of the music faculty: A comparative perspective. Nature Neuroscience, 6, 663-668.

Hinde, R. A., \& Steel, E. (1976). The effect of male-song on an estrogen-dependent behaviour in the female canary (Serinus canarius). Hormones and Behavior, 7, 293-304.

Hock, H. H. (1989). Principles of historical linguistics (2nd ed.). The Hague: Mouton.

Hockett, C. F. (1960). Logical considerations in the study of animal communication. In W. E. Lanyon \& W. N. Tavolga (Eds.), Animal sounds and communication. Washington, DC: American Institute of Biological Sciences.

Hoelzel, A. R. (Ed.). (2002). Marine mammal biology: An evolutionary approach. Oxford: Blackwell.

Homer, S., \& Selman, A. (2001). Computability and complexity theory. New York: Springer.

Huron, D. (2001). Is music an evolutionary adaptation?. Annals of the New York Academy of Sciences 930, 43-61.

Husain, G., Thompson, W. F., \& Schellenberg, E. G. (2002). Effects of musical tempo and mode on arousal, mood, and spatial abilities. Music Perception, 20, 151-171.

Huyge, D. (1990). Mousterian skiffle? Note on a middle palaeolithic engraved bone from Schulen, Belgium. Rock Art Research, 7, 125-132.

Hyde, J. S., \& Linn, M. C. (1988). Gender differences in verbal ability: a meta-analysis. Psychological Bulletin, 104, 53-69.

Insley, S. J. (2000). Long-term vocal recognition in the northern fur seal. Nature, 406, 404-405.

Jackendoff, R., \& Lerdahl, F. (in press). The capacity for music: What is it, and what's special about it? Cognition, this volume, doi:10.1016/j.cognition.2005.11.005.

Janik, V. M., \& Slater, P. B. (1997). Vocal learning in mammals. Advances in the Study of Behavior, 26, 59-99.

Jarvis, E. D. (2004). Learned birdsong and the neurobiology of human language. Annals of the New York Academy of Sciences, 1016, 749-777.

Jarvis, E. D., \& Nottebohm, F. (1997). Motor-driven gene expression. Proceedings of the National Academy of Sciences United Sciences of America, 94(8), 4097-4102.

Judd, T. (1988). The varieties of musical talent. In L. K. Obler \& D. Fein (Eds.), The exceptional brain: Neuropsychology of talent and special abilities (pp. 127-155). New York: Guilford Press.

Juslin, P., \& Sloboda, J. A. (Eds.). (2001). Music and emotion: Theory and research. Oxford: Oxford University Press.

Juslin, P. N., \& Laukka, P. (2003). Communication of emotions in vocal expression and music performance: Different channels, same code?. Psychological Bulletin 129, 770-814.

King, A. S. (1989). Functional anatomy of the syrinx. In A. S. King \& J. McLelland (Eds.). Form and function in birds (4, pp. 105-192). New York: Academic Press.

Kneutgen, J. (1970). Eine Musikform und ihre biologische Funktion. Ueber die Wirkungsweise der Wiegenlieder [The biological function of a category of music: On the effect of lullabies]. Zeitschrift für Experimentelle und Angewandte Psychologie, 17, 245-265.

Koelsch, S., Gunter, T. C., Cramon, D. Y. v., Zysset, S., Lohmann, G., \& Friederici, A. D. (2002). Bach speaks: A cortical "language-network" serves the processing of music. NeuroImage, 17, 956-966. 


\section{ARTICLE IN PRESS}

Koelsch, S., Gunter, T. C., Friederici, A. D., \& Schröger, E. (2000). Brain indices of music processing: "Non-musicians" are musical. Journal of Cognitive Neuroscience, 12, 520-541.

Koelsch, S., Kasper, E., Sammler, D., Schulze, K., Gunter, T. C., \& Friederici, A. D. (2004). Music, language, and meaning: Brain signatures of semantic processing. Nature Neuroscience, 7, 511-514.

Kriner, E., \& Schwabl, H. (1991). Control of winter song and territorial aggression of female robins (Erithacus rubecula). Ethology, 87, 37-44.

Krings, M., Stone, A., Schmitz, R., Krainitzki, H., Stoneking, M., \& Pääbo, S. (1997). Neandertal DNA sequences and the origin of modern humans. Cell, 90, 19-30.

Kroodsma, D. E., \& Byers, B. E. (1991). The function(s) of bird song. American Zoologist, 31, 318-328.

Kunej, D., \& Turk, I. (2000). New perspectives on the beginnings of music: Archaeological and musicological analysis of a middle Paleolithic bone "flute. In N. L. Wallin, B. Merker, \& S. Brown (Eds.), The origins of music (pp. 235-268). Cambridge, Mass: The MIT Press.

Kunst, J. (1959). Ethnomusicology: A study of its nature, its problems, methods and representative personalities to which is added a bibliography (3rd ed.). The Hague: Martinus Nijhoff.

Kunst, J. (1974). Ethnomusicology. The Hague: Martinus Nijhoff.

Labov, W. (1994). Principles of linguistic change. Volume 1: Internal factors. Oxford: Basil Blackwel.

Lachlan, R. F. (1999). Cultural evolution of song in theory and in chaffinches Fringilla coelebs. Unpublished $\mathrm{PhD}$, University of St. Andrews, St. Andrews, UK.

Langmore, N. E. (1998). Functions of duet and solo songs of female birds. Trends in Ecology and Evolution, 13, 136-140.

Langmore, N. E. (2000). Why female birds sing. In Y. Espmark, T. Amundsen, \& G. Rosenqvist (Eds.), Signalling and signal design in animal communication (pp. 317-327). Trodheim, Norway: Tapir Academic Press.

Larson, C. R., Sutton, D., Taylor, E. M., \& Lindeman, R. (1973). Sound spectral properties of conditioned vocalizations in monkeys. Phonetica, 27, 100-112.

Livingstone, F. B. (1973). Did the Australopithecines sing?. Current Anthropology 14(1-2), 25-29.

Logan, D. (1983). Reproductively dependent song cyclicity in mated male mocking brids (Mimus polyglottos). Auk, 100, 404-413.

MacLarnon, A., \& Hewitt, G. (1999). The evolution of human speech: The role of enhanced breathing control. American Journal of Physical Anthropology, 109, 341-363.

Marler, P. (1970a). Birdsong and speech development: could there be parallels?. American Scientist 58, 669-673.

Marler, P. (1970b). A comparative approach to vocal learning: song development in white-crowned sparrows. Journal of Comparative Physiological Psychology Monographs, 71, 1-25.

Marler, P. (1976). An ethological theory of the origin of vocal learning. Annals of the New York Academy of Sciences, 280, 386-395.

Marler, P. (1984). Song learning: Innate species differences in the learning process. In P. Marler \& H. S. Terrace (Eds.), The biology of learning (pp. 289-309). Berlin, Germany: Springer-Verlag.

Marler, P. (1987). Sensitive periods and the roles of specific and general sensory stimulation in birdsong learning. In J. Rauschecker \& P. Marler (Eds.), Imprinting and cortical plasticity (pp. 99-135). New York, NY: Springer-Verlag.

Marler, P. (2000). Origins of music and speech: Insights from animals. In N. L. Wallin, B. Merker, \& S. Brown (Eds.), The origins of music (pp. 31-48). Cambridge, Mass: The MIT Press.

Marler, P., \& Slabbekoorn, H. (2004). Nature's music: The science of birdsong. New York: Academic Press.

Maynard Smith, J. (1964). Group selection and kin selection. Nature, 201, 1145-1147.

McCulloch, S., Pomeroy, P. P., \& Slater, P. J. B. (1999). Individually distinctive pup vocalizations fail to prevent allo-suckling in grey seals. Canadian Journal of Zoology, 77(5), 716-723.

McDermott, J., \& Hauser, M. D. (2005). The origins of music: Innateness, uniqueness, and evolution. Music Perception, 23(1), 29-59.

McDonald, M. V. (1989). Functions of song in Scott's seaside sparrows, Ammodrammus maritimus peninsulae. Animal Behavior, 38, 468-485.

Merker, B. (1999). Synchronous chorusing and the origins of music. Musicae Scientiae, Special Issue 19992000, 59-74. 
Merker, B. (2000). Synchronous chorusing and human origins. In N. L. Wallin, B. Merker, \& S. Brown (Eds.), The origins of music (pp. 315-327). Cambridge, Mass: The MIT Press.

Merker, B. (2002). Music: The missing Humboldt system. Musicae Scientiae, 6, 3-21.

Merriam, A. (1964). The anthropology of music. Evanston, Illinois: Northwestern University Press.

Miller, G. F. (2000). Evolution of music through sexual selection. In N. L. Wallin, B. Merker, \& S. Brown (Eds.), The origins of music (pp. 329-360). Cambridge, Mass: The MIT Press.

Miller, G. F. (2001). The mating mind: How sexual choice shaped the evolution of human nature. New York: Doubleday.

Mithen, S. (2005). The singing neanderthals: The origins of music, language, mind, and body. London: Weidenfeld Nicolson.

Morse, D. H. (1970). Territorial and courtship songs of birds. Nature, 226, 659-661.

Morton, E. S. (1996). A comparison of vocal behavior among tropical and temperate passerine birds. In D. E. Kroodsma \& E. H. Miller (Eds.), Ecology and evolution of acoustic communication in birds (pp. 258-268). Ithaca: Cornell University Press.

Narins, P. M., Lewis, E. R., \& McClelland, B. E. (2000). Hyperextended call repertoire of the endemic Madagascar treefrog, Boophis madagascariensis (Rhacophoridae). Journal of Zoology (London), 250, 283-298.

Nelson, D. E. (1997). Radiocarbon dating of bone and charcoal from Divje Babe I Cave. In I. Turk (Ed.), Mousterian Bone Flute \& Other Finds from Divje Babe I Cave Site in Slovenia (pp. 51-64). Ljubljana: Institut za Arhaeologijo (Znanstvenoraziskovalni Center Sazu).

Nettl, B. (1983). The study of ethnomusicology: Twenty-nine issues and concepts. Urbana: University of Illinois Press.

Nettl, B. (1995). Heartland excursions: Ethnomusicological reflections on schools of music. Chicago: University of Illinois Press.

Nettl, B. (2000). An ethnomusicologist contemplates universals in musical sound and musical culture. In N. L. Wallin, B. Merker, \& S. Brown (Eds.), The origins of music (pp. 463-472). Cambridge, Mass: The MIT Press.

Newport, E. L. (1991). Contrasting conceptions of the critical period for language. In S. Carey \& R. Gelman (Eds.), Epigenesis of mind: Essays on biology and cognition (pp. 113-141). Hillsdale, NJ: Lawrence Erlbaum Associates, Publishers.

Nottebohm, F. (1976). Vocal tract and brain: A search for evolutionary bottlenecks. Annals of the New York Academy of Sciences, 280, 643-649.

Nottebohm, F. (1989). From bird song to neurogenesis. Scientific American, 260, 74-79.

Nottebohm, F. (1999). The anatomy and timing of vocal learning in birds. In M. D. Hauser \& M. Konishi (Eds.), The design of animal communication (pp. 63-110). Cambridge, MA: MIT/Bradford.

Okanoya, K. (2004). The Bengalese finch: A window on the behavioral neurobiology of birdsong syntax. Annals of the New York Academy of Sciences, 1016, 724-735.

Oller, D. K., \& Eilers, R. (1988). The role of audition in infant babbling. Child Development, 59, 441-449.

Owren, M. J., Dieter, J. A., Seyfarth, R. M., \& Cheney, D. L. (1993). Vocalizations of rhesus (Macaca mulatta) and Japanese ( $M$. fuscata) macaques cross-fostered between species show evidence of only limited modification. Developmental Psychobiology, 26, 389-406.

Patel, A. D. (2003). Language, music, syntax and the brain. Nature Neuroscience, 6, 674-681.

Payne, K. (2000). The progressively changing songs of humpback whales: A window on the creative process in a wild animal. In N. L. Wallin, B. Merker, \& S. Brown (Eds.), The origins of music (pp. 135-150). Cambridge, Mass: The MIT Press.

Payne, K. B., \& Payne, R. S. (1985). Large scale changes over 19 years in songs of humpback whales in Bermuda. Zeitschrift für Tierpsychologie, 68, 89-114.

Payne, R., \& McVay, S. (1971). Songs of humpback whales. Science, 173, 583-597.

Peretz, I., Ayotte, J., Zatorre, R. J., Mehler, J., \& Ahad, P. (2002). Congenital amusia: A disorder of finegrained pitch discrimination. Neuron, 33, 185-191.

Peretz, I., \& Hyde, K. L. (2003). What is specific to music processing? Insights from congenital amusia. Trends in Cognitive Sciences, 7, 336-362.

Peretz, I., \& Zatorre, R. J. (2005). Brain organization for music processing. Annual Review of Psychology. 


\section{ARTICLE IN PRESS}

W.T. Fitch / Cognition $x x x$ (2006) $x x x-x x x$

Peretz, I., \& Zatorre, R. J. (Eds.). (2003). The cognitive neuroscience of music. Oxford: Oxford University Press.

Pinker, S. (1997). How the mind works. New York: Norton.

Porter, D., \& Neuringer, A. (1984). Music discriminations by pigeons. Journal of Experimental Psychology: Animal Behavior Processes, 10, 138-148.

Pressing, J. (1998). Cognitive complexity and the structure of musical patterns. Noetica, 3(8), 1-8.

Ralls, K., Fiorelli, P., \& Gish, S. (1985). Vocalizations and vocal mimicry in captive harbor seals, Phoca vitulina. Canadian Journal of Zoology, 63, 1050-1056.

Randall, J. A. (1997). Species-specific footdrumming in kangaroo rats: Dipodomys ingens, D. deserti, $D$. spectabilis. Animal Behaviour, 54, 1167-1175.

Raven, H. C. (1950). The anatomy of the gorilla. New York: Columbia University Press.

Ray, G. C., \& Watkins, W. A. (1975). Social function of underwater sounds in the walrus Odobenus rosmarus. Rapports et Procés-Verbaux des Réunions, Conseil internationale pour l' exploration de la mer, $169,524-526$.

Reeve, H. K., \& Sherman, P. (1993). Adaptation and the goals of evolutionary research. Quarterly Review of Biology, 68, 1-32.

Révész, G. (1941). Der Ursprung der Musik. Internationales Archiv für Ethnographie, 40, 70-75.

Richman, B. (1993). On the evolution of speech: Singing as the middle term. Current Anthropology, 34, 721-722.

Riebel, K. (2003). The 'mute' sex revisited: Vocal production and perception learning in female songbirds. Advances in the Study of Behavior, 33, 49-86.

Rissanen, J. (1997). Stochastic complexity in learning. Journal of Computer and System Sciences, 55, 89-95.

Ritchison, G. (1983). The function of singing in female black-headed grosbeaks (Pheucticus melanocephalus): Family group maintenance. Auk, 100, 105-116.

Ritchison, G. (1986). The singing behavior of female northern cardinals. Condor, 88, 156-159.

Rivers, J. W., \& Kroodsma, D. E. (2000). Singing behavior of the hermit thrush. Journal of Field Ornithology, 71, 467-471.

Roederer, J. G. (1984). The search for a survival value for music. Music Perception, 1, 350-356.

Sachs, C. (1940). The history of musical instruments. New York: W. W. Norton.

Schaller, G. B. (1963). The mountain gorilla. Chicago: University of Chicago Press.

Schellenberg, E. G., \& Trehub, S. E. (2003). Good pitch memory is widespread. Psychological Science, 14, 262.

Scholes, P. A. (1938). Bird Music, Oxford Companion to Music. Oxford: Oxford University Press.

Scothern, P. M. T. (1992). The Music-Archaeology of the Palaeolithic Within its Cultural Setting. Unpublished Ph.D., University of Cambridge, Cambridge.

Searcy, W. A., \& Yasukawa, K. (1996). Song and female choice. In D. E. Kroodsma \& E. H. Miller (Eds.), Ecology and evolution of acoustic communication in birds (pp. 454 473). Ithaca: Cornell University Press.

Shmulevich, I., \& Povel, D.-J. (2000). Measures of temporal pattern complexity. Journal of New Music Research, 29, 61-69.

Simon, H. A. (1962). The architecture of complexity. Proceedings of the American Philosophical Society, $106,467-482$.

Simon, H. A. (1972). Complexity and the representation of patterned sequences of symbols. Psychological Review, 79, 369-382.

Sjare, B., Stirling, I., \& Spencer, C. (2003). Structural variation in the songs of Atlantic walruses breeding in the Canadian High Arctic. Aquatic Mammals, 29, 297-318.

Slater, P. J. B. (2001). Animal music. In S. Sadie (Ed.), The new Grove dictionary of music and musicians (pp. 682-686). London: Macmillan.

Sloboda, J. A. (1985). The musical mind: The cognitive psychology of music. Oxford: Clarendon.

Smith, D. G. (1979). Male singing ability and territory integrity in red-winged blackbirds (Agelaius phoeniceus). Behaviour, 68, 193-206. 
Sober, E., \& Wilson, D. S. (1998). Unto others: The evolution and psychology of unselfish behavior. Cambridge MA: Harvard University Press.

Stark, R. D., Dodenhoff, D. J., \& Johnson, E. V. (1998). A quantitative analysis of woodpecker drumming. Condor, 100, 350-356.

Steele, K. M., Bass, K. E., \& Crook, M. D. (1999). The mystery of the Mozart effect: Failure to replicate. Psychological Science, 10, 366-369.

Studdert-Kennedy, M., \& Goldstein, L. (2003). Launching language: The gestural origins of discrete infinity. In M. Christiansen \& S. Kirby (Eds.), Language evolution (pp. 235-254). Oxford: Oxford Unviersity Press.

Sundberg, J. (1987). The science of the singing voice. Dekalb, Illinois: Northern Illinois University Press.

Suthers, R. A. (1990). Contributions to birdsong from the left and right sides of the intact syrinx. Nature, $347,473-477$.

Suthers, R. A. (1999). The motor basis of vocal performance in songbirds. In M. D. Hauser \& M. Konishi (Eds.), The design of animal communication (pp. 37-62). Cambridge, MA: MIT/Bradford.

Tchernichovski, O., Mitra, P. P., Lints, T., \& Nottebohm, F. (2001). Dynamics of the vocal imitation process: How a zebra finch learns its song. Science, 291, 2564-2569.

Teramitsu, I., Kudo, L. C., London, S. E., Geschwind, D. H., \& White, S. A. (2004). Parallel FoxP1 and FoxP2 expression in songbird and human brain predicts functional interaction. Journal of Neuroscience, 24, 3152-3163.

Thomas, J. A., \& Golladay, C. L. (1996). Geographic variation in leopard seal (Hydrurga leptonyx) underwater vocalizations. In R. Kastelein, J. A. Thomas, \& P. E. Nachtigall (Eds.), Sensory systems of aquatic mammals. Woerden, The Netherlands: DeSpil Publishers.

Thomas, J. A., \& Stirling, I. (1983). Geographic variation in the underwater vocalizations of Weddell seals (Leptonychotes weddelli) from Palmer Peninsula and McMurdo Sound, Antarctica. Canadian Journal of Zoology, 61, 2203-2212.

Thompson, N. S., Abbey, E., Wapner, J., Logan, C., Merritt, P. G., \& Pooth, A. (2000). Variation in the bout structure of northern mockingbird (Mimus polyglottos) singing. Bird Behavior, 13(2), 93-98.

Thompson, W. F., Schellenberg, E. G., \& Husain, G. (2001). Arousal, mood, and the Mozart effect. Psychological Science, 12, 248-251.

Tinbergen, N. (1963). On aims and methods of ethology. Zeitschrift für Tierpsychologie, 20, 410-433.

Titon, J. T., Koetting, J. T., McAllester, D. P., Reck, D. B., \& Slobin, M. (Eds.). 1984. Worlds of Music: An introduction to the music of the world's peoples. New York: Schirmer Books.

Todt, D., \& Hultsch, H. (1982). Impairment of vocal exchange in the monogamous duet-singer Cossypha heuglini (Turdidae): Effects on pairbond maintenance. Zeitschrift für Tierpsychologie, 60, 265-274.

Trainor, L. J. (2005). Are there critical periods for musical development? Developmental Psychobiology, 46, $262-278$.

Trainor, L. J., McDonald, K. L., \& Alain, C. (2002). Automatic and controlled processing of melodic contour and interval information measured by electrical brain activity. Journal of Cognitive Neuroscience, 14, 430-442.

Trainor, L. J., \& Schmidt, L. A. (2003). Processing emotions induced by music. In I. Peretz \& R. J. Zatorre (Eds.), The cognitive neuroscience of music (pp. 310-324). Oxford: Oxford University Press.

Trehub, S. E. (2000). Human processing predispositions and musical universals. In N. L. Wallin, B. Merker, \& S. Brown (Eds.), The origins of music (pp. 427-448). Cambridge, Mass: The MIT Press.

Trehub, S. E. (2003). Musical predispositions in infancy: An update. In I. Peretz \& R. J. Zatorre (Eds.), The cognitive neuroscience of music (pp. 3-20). Oxford: Oxford University Press.

Trehub, S. E., \& Nakata, T. (2001). Emotion and music in infancy. Musicae Scientiae, Special Issue 20012002, 37-59.

Trehub, S. E., \& Trainor, L. J. (1998). Singing to infants: Lullabies and play songs. Advances in Infant Research, 12, 43-77.

Turk, I. (Ed.). (1997). Mousterian Bone Flute Other Finds from Divje Babe I Cave Site in Slovenia. Ljubljana:. Institut za Arhaeologijo (Znanstvenoraziskovalni Center Sazu).

Van Parijs, S. M. (2003). Aquatic mating in pinnipeds: A review. Aquatic Mammals, 29, 214-226. 


\section{ARTICLE IN PRESS}

W.T. Fitch / Cognition $x x x$ (2006) $x x x-x x x$

Vihman, M. M. (1986). Individual differences in babbling and early speech: Predicting to age three. In B. Lindblom \& R. Zetterström (Eds.), Precursors of early Speech (pp. 95-112). New York, NY: Stockton Press.

Wallin, N. L., Merker, B., \& Brown, S. (2000). The origins of music. Cambridge, Mass: The MIT Press.

Watkins, W. A., \& Schevill, W. E. (1977). Sperm whale codas. Journal of the Acoustical Society of America, $62,1485-1490$.

Webb, D. M., \& Zhang, J. (2005). FoxP2 in song-learning birds and vocal-learning mammals. Journal of Heredity, 96, 212-216.

Weng, G., Bhalla, U. S., \& Iyengar, R. (1999). Complexity in biological signalling systems. Science, 284, 92-96.

West-Eberhard, M. J. (1992). Adaptation: Current usages. In E. F. Keller \& E. A. Lloyd (Eds.), Keywords in evolutionary biology (pp. 170-179). Cambridge, Massachusetts: Harvard University Press.

Wickler, W. (1980). Vocal duetting and the pair bond: 1. Coyness and partner commitment: A hypothesis. Zeitschrift Tierpsychologie, 52, 201-209.

Williams, G. C. (1966). Adaptation and natural selection. Princeton, NJ: Princeton University Press.

Williams, L. (1967). The dancing chimpanzee: A study of the origins of primitive music. New York: Norton.

Wing, A. H. (1951). Notes on the song series of a hermit thrush in the Yukon. Auk, 68, 189-193.

Wood, G. A. (1984). Tool use by the Palm Cockatoo Probosciger aterrimus during display. Corella, 8 , 94-95.

Wood, G. A. (1988). Further field observations of the Palm Cockatoo Probosciger aterrimus in the Cape York Peninsula, Queensland. Corella, 12, 48-52.

Wray, A. (2002). Formulaic language and the lexicon. Cambridge: Cambridge University Press.

Wright, A. A., Rivera, J. J., Hulse, S., Shyan, M., \& Neiworth, J. J. (2000). Music perception and octave generalization in rhesus monkeys. Journal of Experimental Psychology: General, 129(3), 291-307.

Zatorre, R. J., \& Peretz, I. (Eds.). (2001). The Biological Foundations of Music (Vol. 930). New York: New York Academy of Sciences. 